\title{
Modeling and Verification of a Diamond-Shape Narrow-Tilting Vehicle
}

\author{
Jin-Chern Chiou and Chih-Liang Chen
}

\begin{abstract}
The authors use planar multibody system dynamics to model an intelligent personal mobility (IPM) narrow-tilting vehicle (NTV) with four wheels arranged in a diamond configuration. A planar multibody system tire model is used to represent groundvehicle interaction. In addition to analyzing the roll plane dynamics, the proposed model supports the measuring of joint reaction forces (a difficult task with actual vehicles) to assist in advanced controller and mechanical system design. We also propose a separate calculation method using two acceleration sensors and one angular position sensor for the purpose of obtaining ground forces. Results from model verification tests (i.e., comparisons with actual data from a slalom test) indicate that the proposed IPM model performed with a high degree of accuracy.
\end{abstract}

Index Terms-Modeling and verification, multibody dynamics, narrow-tilting vehicle (NTV).

\section{INTRODUCTION}

$\mathbf{T}$ HE PROBLEM of oil shortages is currently a major economic concern; another important issue affecting daily life in many cities is manufacturing vehicles that are energy efficient. Furthermore, traffic congestion is a growing problem in cities all over the world. Building highways to match the growth rate of vehicles is not an easy task; the efficient utilization of existing highways can play a major role in addressing this problem [1], [2]. In the United States, the average number of occupants per vehicle is 1.58 [3]. This means vehicles in that country are underutilized in terms of unnecessary weight and fuel consumption; in addition, the amount of pollution per vehicle occupant remains high.

One emerging line of research and development is aimed at creating vehicles for a maximum of two passengers, with a configuration of one sitting behind the other. Using track widths as narrow as $1 \mathrm{~m}$, these vehicles have great potential for reducing fuel consumption, doubling road capacity (since two can fit side-by-side in the space of a single lane on today's highways),

Manuscript received April 18, 2008; revised August 7, 2008. Current version published December 17, 2008. Recommended by Technical Editor J. Wagner. This work was supported by the Intelligent Personal Mobility (IPM) Research Group (Light Electric Vehicle Project), Industrial Technology Research Institute, Taiwan, R.O.C. The work also was supported in part by Ministry of Education, Taiwan, R.O.C., under Contract 97W802 (5-year, 50-billion NTD development program) and by National Science Council, Taiwan, R.O.C., under Contract 97-2220-E-009-026.

J.-C. Chiou is with the Department of Electrical and Control Engineering, National Chiao Tung University, Hsin Chu 30010, Taiwan (e-mail: chiou@cc.nctu.edu.tw).

C.-L. Chen is with the Department of Electric and Control Engineering, National Chiao-Tung University, Hsin Chu 30010, Taiwan, and also with the Mechanical Industry Research Laboratories, Industrial Technology Research Institute of Taiwan, Hsin Chu 30010, Taiwan (e-mail: elvison.ece91g@nctu.edu.tw).

Color versions of one or more of the figures in this paper are available online at http://ieeexplore.ieee.org.

Digital Object Identifier 10.1109/TMECH.2008.2004769
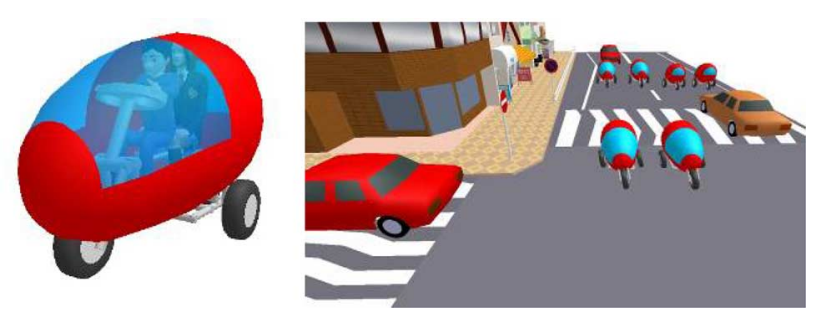

Fig. 1. NTV concept.

and increasing parking capacity (see Fig. 1). However, since these vehicles are much more narrow than even the smallest cars in current use [hence the name, narrow-tilting vehicles (NTVs)], an engineering solution must be found for the problem of maintaining cornering stability on road surfaces over a wide range of speeds.

NTVs must be tall enough to provide good highway visibility for drivers, and since tall narrow vehicles have high centers of gravity, track width ratios are problematic [4]. If NTVs are to handle curves at all operating speeds, they require a tilt function that mimics two-wheeled vehicles, but does not require special driver skills (as in the case of motorcycle operators). The tilt function should also help protect drivers from accidentally rolling in situations where they suddenly come in contact with lateral road slopes or potholes.

Several NTV prototypes have been developed by the automotive industry over the past 50 years. The Gyron, Ford's earliest NTV design, used a $180 \mathrm{lb}$ gyroscope for cornering stabilization and featured retractable wheel pods for parked vehicles [5]; the weight of the gyroscope is now considered excessive. In the 1970s, General Motors developed the three-wheeled Lean Machine, consisting of a nontilting rear engine pod attached to a rotating body module [5]. A driver-operated foot pedal controlled a tilt-stabilizing actuator. Also in the 1970s, BSA developed a vehicle based on James Staley and William Hillman's Ariel tricycle, in which driver movement controlled tilt [6]. Yamaha, Kawasaki, and Honda all developed similar prototypes the following decade [7]-[9].

There are several NTV-concept vehicles currently under development. The Mercedes-Benz F-300 Life-jet tilt control system makes use of a hydraulic actuator. Design details are proprietary, but reports indicate that the F-300 has a relatively wide track width (perhaps to accommodate the actuator's high tilting torque), which conflicts with the goal of building narrow vehicles to increase the carrying capacities of existing roads and highways. Carver Europe is working on a Carver One vehicle that also uses a hydraulic actuator. According to the Carver Web site (http://www.carver-worldwide.com), its engineers are trying to find a balance between speed and weight. Toyota's 


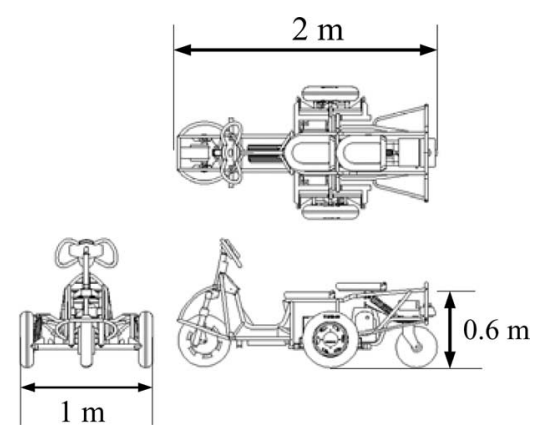

Fig. 2. Overall IPM dimensions.

state-of-the-art i-Swing has a switching function between two modes: a two-wheel mode for low speeds and a three-wheel mode for high speeds. The i-Swing also has artificial intelligence software for learning individual driver habits, and a pedal-controlled tilting mechanism that allows operators to turn in the same manner as snowboarders. However, it is not considered convenient for daily use because of its small size, thin shell, and low power $(20 \mathrm{~km} / \mathrm{h}$ maximum speed). Other private firms working on prototypes are the Narrow Car Company (with its NARO model) and COVCO, Ltd. (Micro Max). Several academic research centers are making contributions to the NTV effort, with perhaps the best known being the European compact low emission vehicle for urban transport (CLEVER).

In this paper, we will describe: 1) our proposal for an intelligent personal mobility (IPM) vehicle for urban transportation, one that features low weight and a vehicular tilting motion and 2) our use of multibody dynamic system theory to construct a model whose primary purpose is to identify dangerous driving situations to be addressed in future vehicle design efforts. We will also report and compare our results from numerical simulations and actual driving tests.

\section{Vehicle StRUCTURE}

\section{A. IPM Prototype Design and Manufacture}

The IPM NTV is a major project of the Mechanical Industry Research Laboratories of the Industrial Technology Research Institute of Taiwan. Our diamond-shaped prototype has one front wheel for steering, two side wheels, and one castor rear wheeleach with its own shock absorber. Our IPM's weight is less than $210 \mathrm{~kg}$; overall dimensions are shown in Fig. 2 (all units in this paper are in MKS). Top IPM speed is $53 \mathrm{~km} / \mathrm{h}$; a rotational damper mounted on the castor mechanism restricts the castor rear wheel steering to low speeds, thereby eliminating the potential for shimmying. Its current design does not allow for extra displacement when cornering (on-spot turning), which is considered convenient for parking and driving on urban streets. The parallel four-link suspensions for the two side wheels overcome roll disturbances caused by camber irregularities on road surfaces. As indicated in Figs. 3 and 4, the entire vehicle is capable of tilting around a roll center (see also Appendix A). Tilting limiters have been integrated into the system for driver safety.

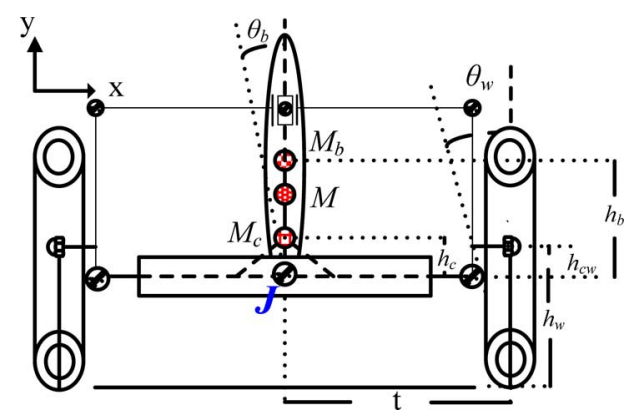

Fig. 3. Simple IPM roll model.

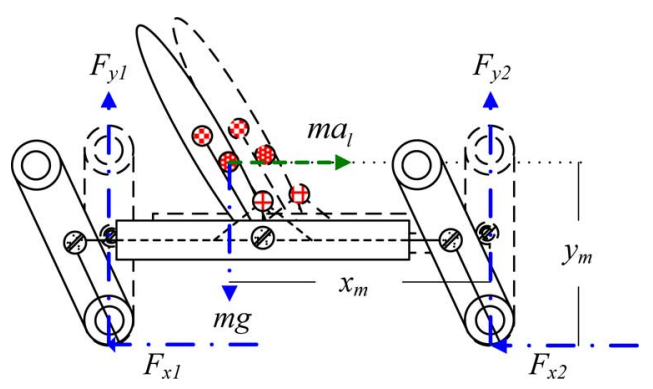

Fig. 4. Simple IPM left turn roll model.

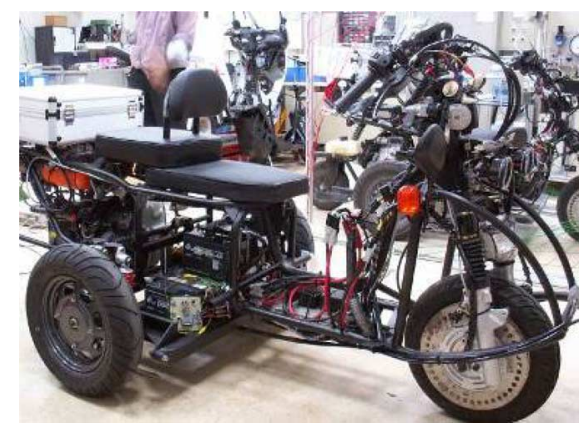

Fig. 5. Assembled IPM.

The front wheel is powered by a commercially available inwheel motor used with electric scooters. Some parts of the body/chassis were designed and/or built by our project group, including a frame for mounting the steering mechanism, rear suspension, and chassis. An original rectangular chassis was used to mount the tilting mechanism, batteries, dampers, side wheels, rear wheel frame, and other vehicle parts. The front fork, shock absorbers, and wheels were taken from commercially available scooters and hand transport carts. A photograph of the assembled vehicle is shown in Fig. 5.

\section{B. Rollover Resistance}

When the IPM tilts, a six-link mechanism provides centripetal force and increases rollover resistance (see Fig. 3). Rollovers result from complex interactions of forces acting on and within vehicles that are influenced by vehicle movement and roadway characteristics. A considerable amount of empirical research exists on this issue. Our design is based on the premise that rollovers can be resisted using quasi-static rollover analysis, 
while neglecting inertial terms and accelerations on the roll plane [4].

A simple roll model for a left turn by a standard four-wheeled automobile is presented in Fig. 4. As shown, the left wheels are closer to the center of the forward-moving track curvature. Assuming that the roadway cross slope is zero, the rolling moment during cornering is smaller on a car with slip motion than on a car without slip motion. Accordingly, at the transience of cornering, we assume that: 1) vehicle wheels are attached to the cornering track of the ground (meaning that the lateral force transmitted from ground friction serves as the centripetal force for cornering) and 2) the centripetal force is transformed into a centrifugal force that acts on the mass center. This effect can be used to obtain the rollover threshold at which a vehicle's wheels will leave the ground [4]. Equation (A11) in Appendix A indicates that our IPM tilting mechanism is capable of resisting larger amounts of lateral acceleration than those experienced by standard narrow nontilting cars. Furthermore, our data indicate that the cornering stability of our IPM NTV equals that of today's mass production cars.

\section{VEHICLE MODELING}

With its tilting capability and four wheels arranged in a diamond shape, the IPM NTV is more complex than standard three- and four-wheeled vehicles in terms of modeling. Whereas most modeling methods for standard vehicles only require system degree of freedom data, our IPM vehicle requires data on joint reaction forces for control and design purposes, making it necessary to adapt a dynamic multibody system modeling procedure for system analysis. Multibody systems distinguish between essential moving and nonmoving parts, the selection of which depends on how they affect system dynamics. They also require joints to constrain relative motion between vehicle sections. Current system equations require data on center of mass, moment of inertia, initial position of mass center, principle body axes, joint types, and locations of joint-body connections. Once the data are collected, differential-algebraic equations (DAEs) are easily constructed and solved [10].

\section{A. Multibody Roll Model}

A three-dimensional multibody dynamic model of our 18joint IPM is shown in Fig. 6. Numbers in brackets indicate body parts whose definitions are given in Appendix B. The roll plane dynamics shown in Fig. 7 were utilized for simplification purposes to obtain our target tilting and rolling characteristics; details are also given in Appendix B. To derive the tire force model for a multibody system, the coordinate system is defined as shown in Fig. 8 (see Appendix C); for purposes of computing simplification, system vectors are shown as column vectors in matrix form [10].

\section{B. Tire Force Model}

In the IPM cycle tire cross section shown in Fig. 9, $P$ designates the central point of the tire section, and $C$ denotes the contact point between the tire and ground. Cycle tire modeling

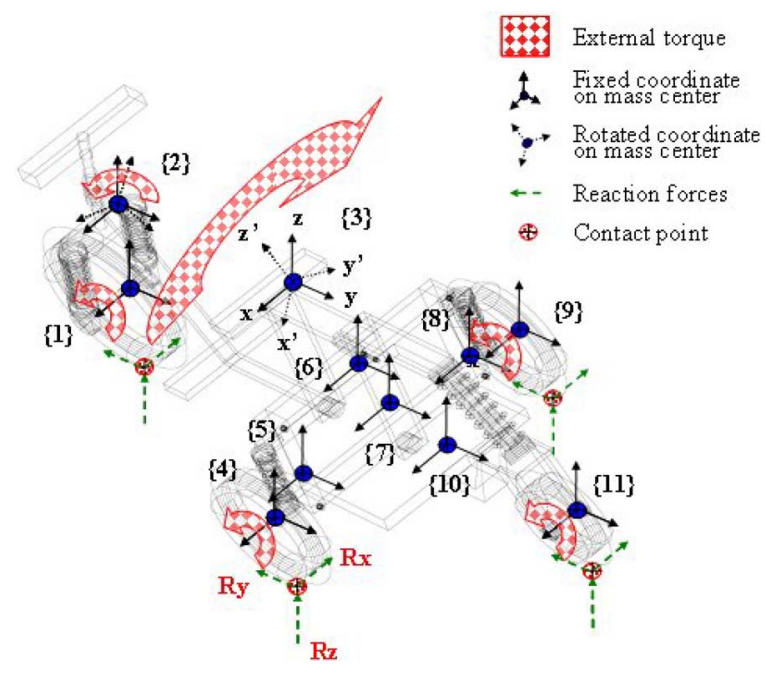

Fig. 6. Three-dimensional multibody IPM model.

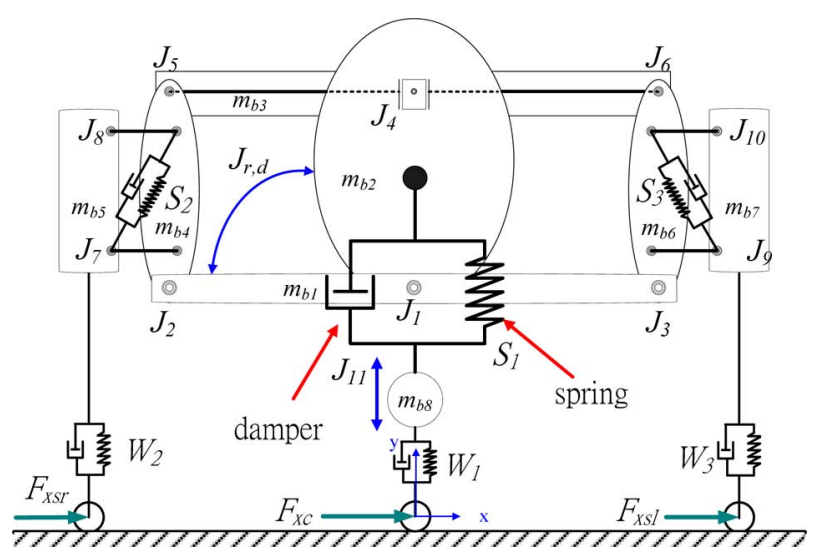

Fig. 7. Multibody IPM roll model, front view.

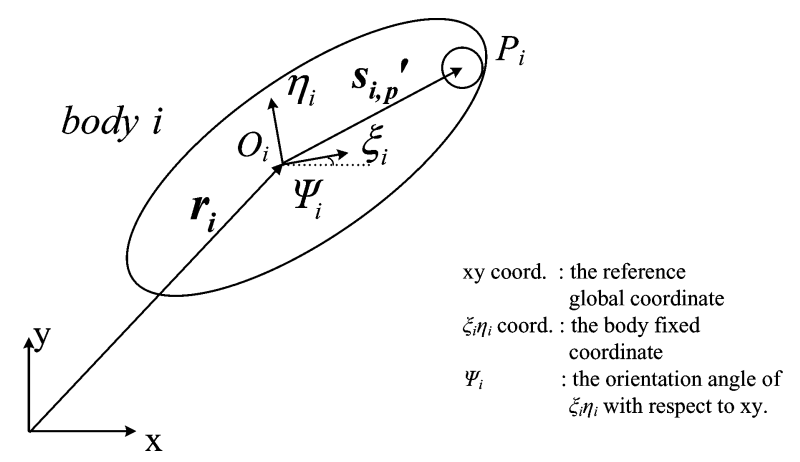

Fig. 8. Cartesian coordinates of point $P_{i}$.

assumes that point $C$ always represents the projection of point $P$ on the ground. In Fig. 10 (illustrating forces that act on the wheel rim), the body number index of the wheel rim and tire is represented by the letter $j$. Point $O_{j}$ (the $\xi_{j} \eta_{j}$ axes origin) is fixed on the mass center of the wheel rim and tire; points $P_{j}$ and $C_{j}$ in this figure are, respectively, similar to points $P$ and $C$ in Fig. 9. $F_{j, x}$ and $F_{j, y}$ denote forces exerted on the mass center of a wheel rim in $x$ - and $y$-directions, respectively; $N_{j}$ denotes the torque exerted on $b o d y j$; and $F_{c j, x}$ denotes the force exerted on 


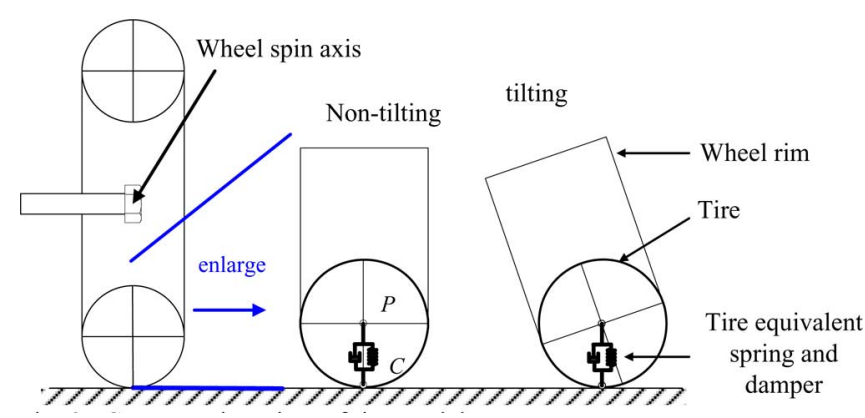

Fig. 9. Cross-sectional view of tire model.

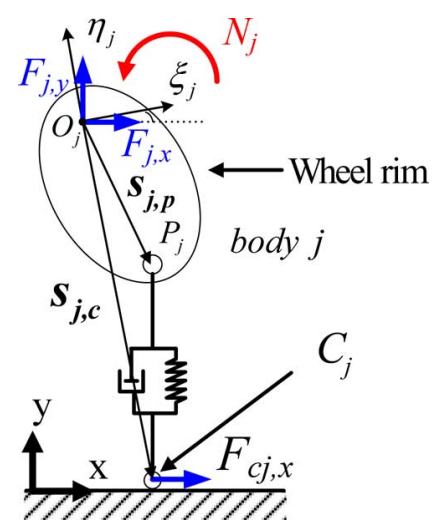

Fig. 10. Model of tire force exerted on wheel rim.

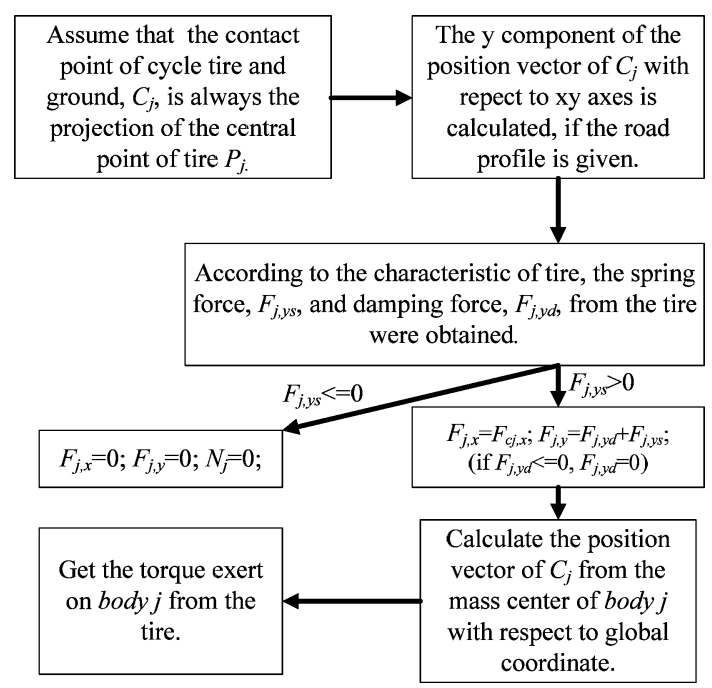

Fig. 11. Flowchart for computing tire force exerted on wheel rim.

the tire from the ground in $x$-direction. A flowchart for computing the forces and torque exerted by the tire on the wheel rim is shown in Fig. 11. How this tire force model was derived for multibody dynamics is explained in Appendix D [(D1)-(D7)].

\section{Model Equations of Motion}

In (1), $\boldsymbol{q}_{i}$ denotes the position and orientation of body $i$. As shown in (2) for $n$ bodies in a system, vector $\boldsymbol{q}$ denotes a combination of $\boldsymbol{q}_{1}, \boldsymbol{q}_{2}, \boldsymbol{q}_{3}, \ldots, \boldsymbol{q}_{n}$. System equations can be

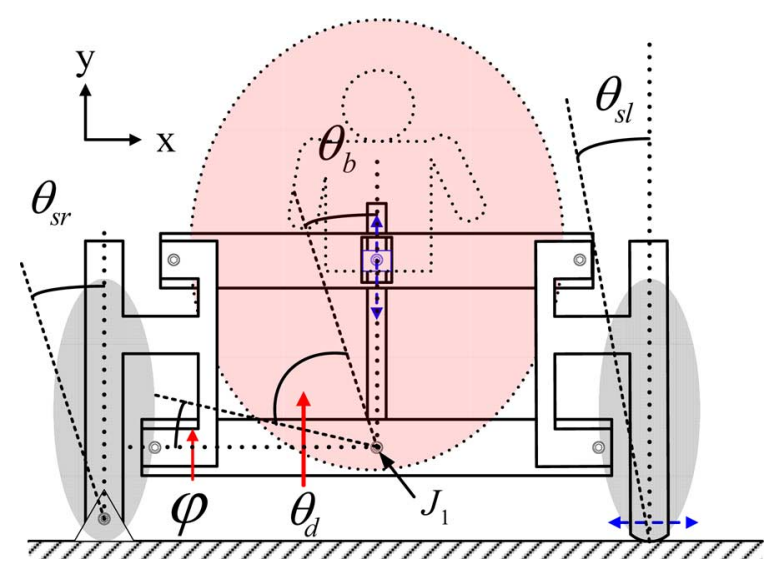

Fig. 12. Kinematic IPM motion.

derived using a Lagrange multiplier according to the dynamics and kinematics of constraint systems [10]. By presenting the combined dynamic and kinematic constraint equations in matrix form, it is possible to derive and express an equation of motion in DAEs form, as shown in (3). In that equation, $\boldsymbol{I}_{\boldsymbol{m}}$ denotes the body mass matrix, $\boldsymbol{\Phi}$ the kinematic constraint equations, $\boldsymbol{\Phi}_{\boldsymbol{q}}$ the Jacobian matrix (taking a partial derivative of $\boldsymbol{\Phi}$ with respect to $\boldsymbol{q}), \boldsymbol{\lambda}$ a Lagrange multiplier vector, $\boldsymbol{Q}$ the external forces exerted on the bodies in a system, and $\gamma$ the right side of kinematic acceleration equations [10]. This motion equation allows IPM dynamics and $\lambda$ to be obtained via numerical simulations. Using $n_{c}$ to represent the number of constraints, $\lambda$ is a $n_{c} \times 1$ vector. $\lambda_{k}$ denotes the Lagrange multiplier of the $k$ th element of $\lambda$, and $\lambda_{k m}$ is defined as a zero vector with the same dimension as $\lambda$. As shown in (4), the $k$ th element of $\lambda_{k m}$ is replaced by $\lambda_{k}$. In (5), $\boldsymbol{R}_{\boldsymbol{k}}$ (a column vector having the same dimension as $\boldsymbol{q}$ ) denotes constraint reaction forces exerted on each body from the $k$ th constraint of the system. Note that constraint reaction forces calculated from joints are very useful for controller and mechanical system design

$$
\begin{aligned}
& \boldsymbol{q}_{i}=\left[x_{i}, y_{i}, \psi_{i}\right]^{T} \\
& \boldsymbol{q}=\left[\begin{array}{llll}
\boldsymbol{q}_{1}^{T} & \boldsymbol{q}_{2}^{T} & \cdots & \boldsymbol{q}_{\boldsymbol{n}}^{T}
\end{array}\right]^{T} \\
& {\left[\begin{array}{cc}
\boldsymbol{I}_{\boldsymbol{m}} & \boldsymbol{\Phi}_{\boldsymbol{q}}^{T} \\
\boldsymbol{\Phi}_{\boldsymbol{q}} & 0
\end{array}\right]\left[\begin{array}{l}
\ddot{\boldsymbol{q}} \\
\lambda
\end{array}\right]=\left[\begin{array}{l}
\boldsymbol{Q} \\
\gamma
\end{array}\right]} \\
& \lambda_{\boldsymbol{k m}}=\left[\begin{array}{lllllll}
0 & \ldots & 0 & \lambda_{k} & 0 & \ldots & 0
\end{array}\right]^{T} \\
& \boldsymbol{R}_{k}=\Phi_{q}^{T} \lambda_{k m} .
\end{aligned}
$$

\section{COMPUTING GROUND FORCES}

We developed a method for obtaining forces from the ground to verify our derived model experimentally. The approximate position of $M$ with respect to $J_{1}$ must be obtained to approximate distances between those forces and $M$. Our tilting mechanism can be simplified as a six-link mechanism, as in Fig. 12. The approximate position of $M$ with vehicular tilting is shown as Fig. 13, and the flowchart used to obtain this approximate position is shown as Fig. 14. All notations for Figs. 12-14 and 


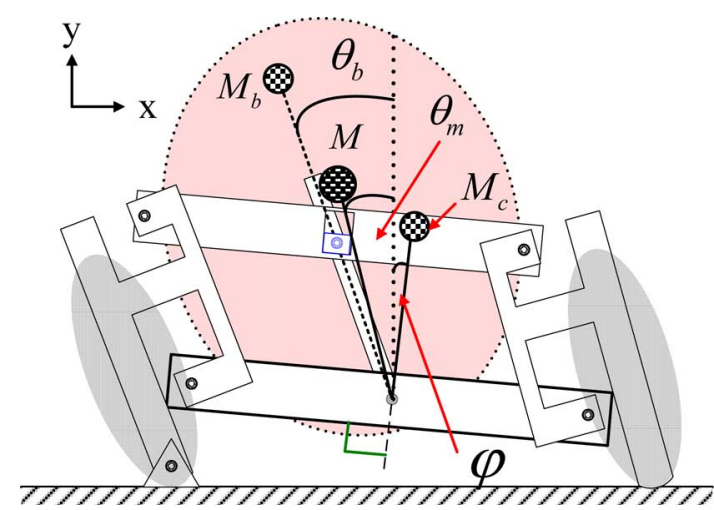

Fig. 13. Approximate position of mass center after kinematic motion.

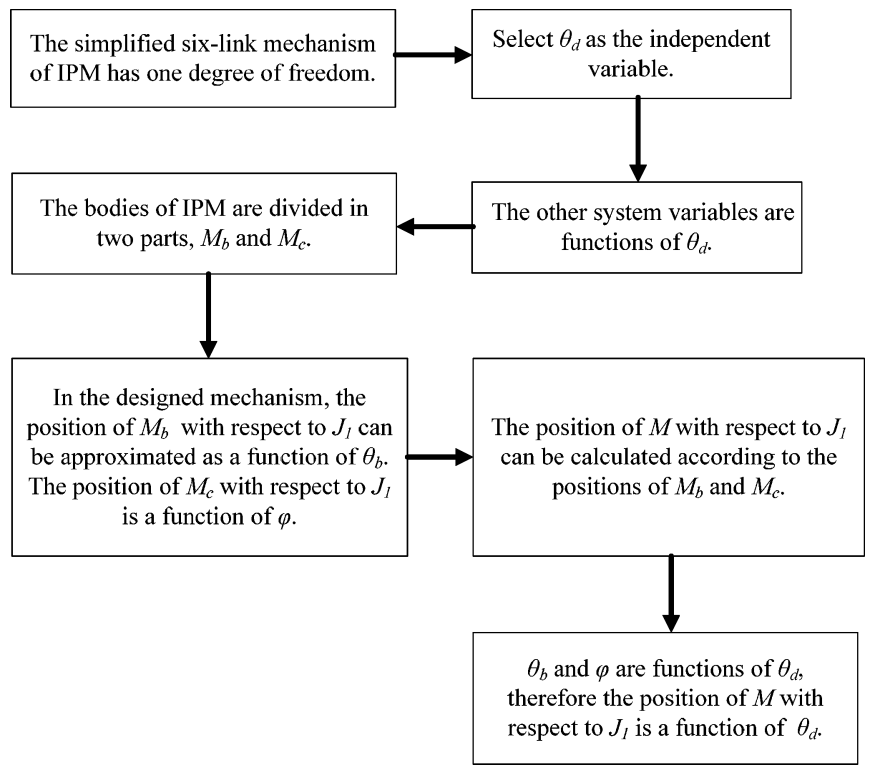

Fig. 14. Flowchart for computing IPM mass center position.

(6)-(13) are given in Appendix E. Since the six-link mechanism has only one degree of freedom, the kinematic motion of the sixlink mechanism can be obtained when a single system variable is given. In the present derivation, $\theta_{d}$ was chosen as an independent variable; as shown in (6)-(9), all remaining variables are functions of $\theta_{d}$. In the simplified mechanism, the position of $M_{b}$ with respect to $J_{1}$ approximates a function of $\theta_{b}$, and the position of $M_{c}$ with respect to $J_{1}$ is a function of $\varphi$. Accordingly, the position of $M$ with respect to $J_{1}$ can be calculated using (10) and (11), and $\theta_{m}$ can be calculated using (12). As shown in (13), $l_{m_{o}}$ can be calculated using the square root of the square sum of $L_{c j, x}$ and $L_{c j, y}$. Note that the following equations are essential for obtaining reaction forces from the ground:

$$
\begin{aligned}
\theta_{b} & =f\left(\theta_{d}\right) \\
\varphi & =f\left(\theta_{d}\right) \\
\theta_{s l} & =f\left(\theta_{d}\right) \\
\theta_{s r} & =f\left(\theta_{d}\right)
\end{aligned}
$$

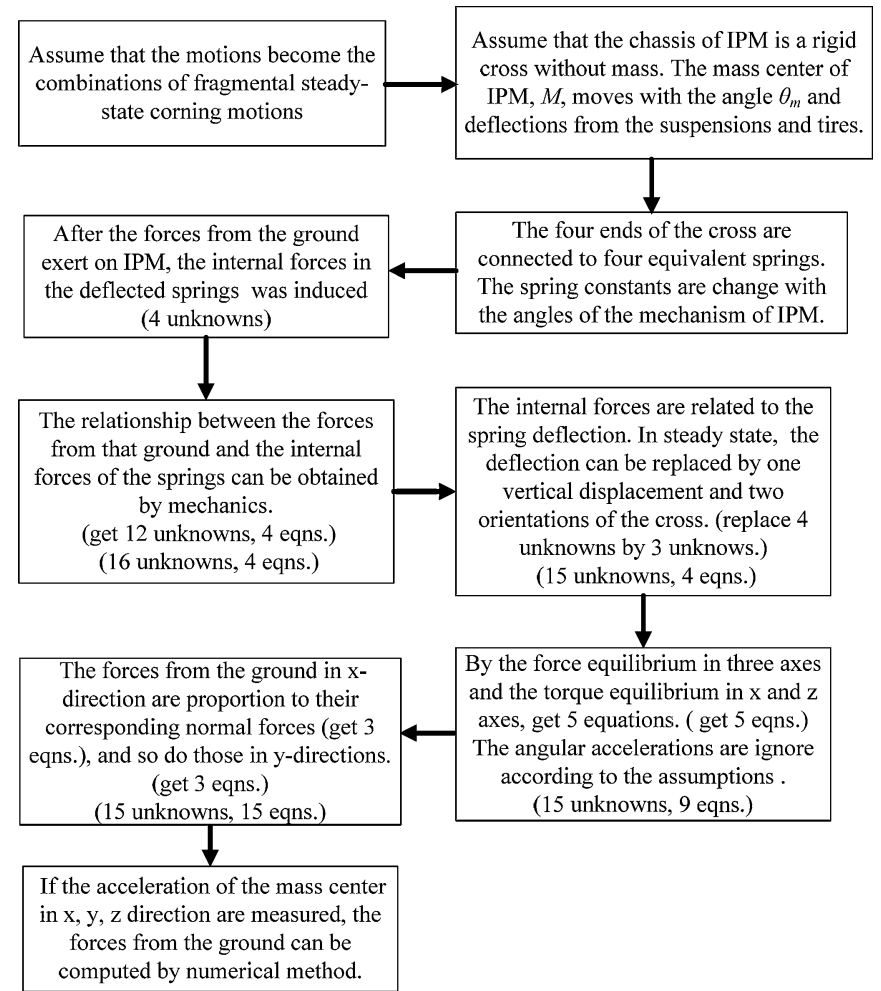

Fig. 15. Flowchart for computing forces from ground.

$$
\begin{aligned}
L_{c J, x} & =\frac{\left[-M_{b} l_{b} \sin \left(\theta_{b}\right)+M_{c} l_{\mathrm{ch}} \sin (\varphi)\right]}{m} \\
L_{c J, y} & =\frac{\left[M_{b} l_{b} \cos \left(\theta_{b}\right)+M_{c} l_{\mathrm{ch}} \cos (\varphi)\right]}{m} \\
\theta_{m} & =-\tan ^{-1}\left(\frac{L_{c, x}}{L_{c, y}}\right)=f\left(\theta_{d}\right) \\
l_{m o} & =\sqrt{L_{c J, x}^{2}+L_{c J, y}^{2}}=f\left(\theta_{d}\right) .
\end{aligned}
$$

A flowchart for computing forces from the ground is presented in Fig. 15. As shown, those forces can be obtained if the three-axis accelerations of the mass center and $\theta_{m}$ are available (see Appendix F). In other words, the combination of (6)(13) and (F1)-(F19) can be used to compute all forces from the ground given the measured $\theta_{d}$ and three-axis accelerations. These forces can also be used as input for an IPM multibody roll model. Note that force $F_{x c}$ is a summation of forces $F_{x f}$ and $F_{x r}$.

\section{SLalom Test}

To verify the model, we created the small (single-curve) slalom course illustrated in Fig. 16. In that figure, $R$ denotes the curve radius, $d$ its width, $H_{1}$ the origin and center of the bottom circle used to design the curve, $H_{2}$ the center the middle circle [at position $(a, b)$ ], and $C_{1}$ the point of tangency of two circles with radius $R$ drawn from $H_{1}$ and $H_{2}$. The position of $C_{1}$ is $(x, y)$. A curve can be drawn given $R$ and $d ;(a, b)$ can be solved by (14), after which (15) and (16) can be obtained. In our 


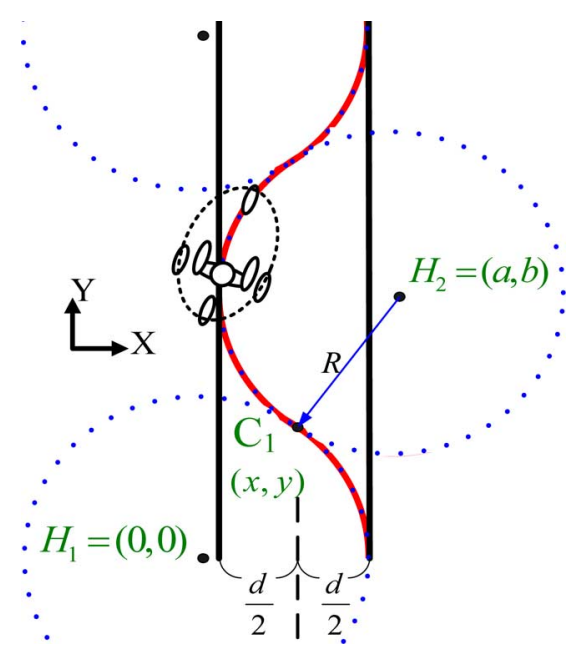

Fig. 16. Curve of designed slalom test.

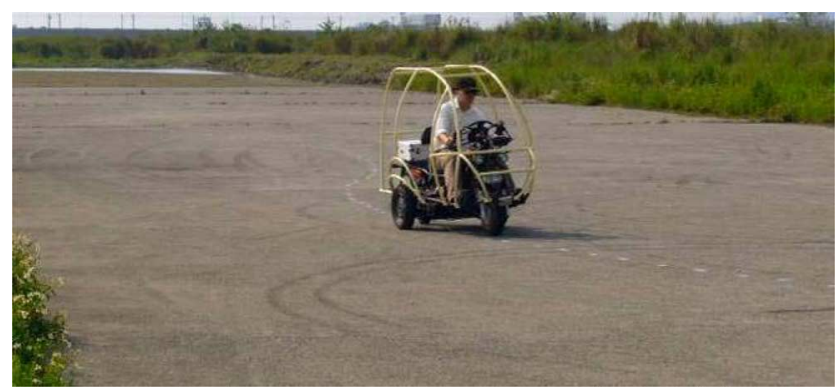

Fig. 17. Slalom test without tilting motions.

road test, $R=25 \mathrm{~m}$ and $d=4 \mathrm{~m}$. Photographs of the course and IPM road test are shown as Figs. 17 (without tilting motion) and 18 (with tilting motion).

$$
\begin{aligned}
& \left\{\begin{array}{l}
2 R-a=d \\
x^{2}+y^{2}=R^{2} \\
a^{2}-2 b y-2 a x+b^{2}+x^{2}+y^{2}=R^{2} \\
x=R-d / 2 \\
y=b / 2
\end{array}\right. \\
& a=2 R-d \\
& b=\sqrt{4 R^{2}-a^{2}} .
\end{aligned}
$$

\section{RESULTS}

Table II shows the position of mass center of the model and the manufactured vehicle in static equilibrium. The result shows the position of the mass center of the model is close to the real vehicle.

For dynamic analysis, we drove our assembled IPM NTV with and without tilting at four speeds: 4.7, 5.5, 6.9, and $8.0 \mathrm{~m} / \mathrm{s}$. Since the tilting actuator and corresponding controller are still being developed, the tilting motions in these tests were initiated by the driver. In addition to verifying the model, a second goal for these tests was to collect data on driver tilting behaviors that can be used as future design references. Data were collected using one

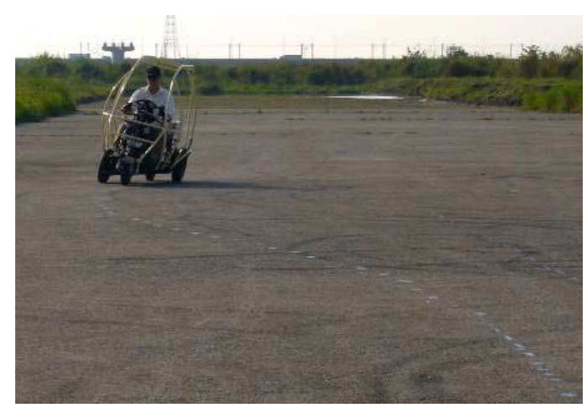

Fig. 18. Slalom test with tilting motions.

TABLE I

JOINTS, JOINT TYPES, NUMBERS OF CONSTRAINT EQUATIONS, AND CONNECTING BODIES

\begin{tabular}{c||c|c|c}
\hline The joint & Type of joint & no. of constraint eqn. & $\begin{array}{c}\text { Connecting bodies } \\
{[\text { body-i, body-j] }}\end{array}$ \\
\hline \hline$J_{1}$ & $\mathrm{r}$ & 2 & {$\left[m_{b 1}, m_{b 2}\right]$} \\
\hline$J_{2}$ & $\mathrm{r}$ & 2 & {$\left[m_{b 1}, m_{b 4}\right]$} \\
\hline$J_{3}$ & $\mathrm{r}$ & 2 & {$\left[m_{b 1}, m_{b 6}\right]$} \\
\hline$J_{4}$ & $\mathrm{r}-\mathrm{t}$ & 1 & {$\left[m_{b 2}, m_{b 3}\right]$} \\
\hline$J_{5}$ & $\mathrm{r}$ & 2 & {$\left[m_{b 3}, m_{b 4}\right]$} \\
\hline$J_{6}$ & $\mathrm{r}$ & 2 & {$\left[m_{b 3}, m_{b 6}\right]$} \\
\hline$J_{7}$ & $\mathrm{r}-\mathrm{r}$ & 1 & {$\left[m_{b 4}, m_{b 5}\right]$} \\
\hline$J_{8}$ & $\mathrm{r}-\mathrm{r}$ & 1 & {$\left[m_{b 4}, m_{b 5}\right]$} \\
\hline$J_{9}$ & $\mathrm{r}-\mathrm{r}$ & 1 & {$\left[m_{b 6}, m_{b 7}\right]$} \\
\hline$J_{10}$ & $\mathrm{r}-\mathrm{r}$ & 1 & {$\left[m_{b 6}, m_{b 7}\right]$} \\
\hline$J_{11}$ & $\mathrm{t}$ & 2 & {$\left[m_{b 2}, m_{b 8}\right]$} \\
\hline
\end{tabular}

Note: $r$ : revolute joints; $t$ : transitional joints; $r$ - $r$ : revolute-revolute composite joints; $r-t$ : revolute-translational composite joints [10].

angular position sensor and two inertia sensors-one located at the mass center of $m_{b 1}$ and the other at the approximated mass center of the other bodies (see Fig. 7). The two Microstrain 3DM-GX1 inertia sensors are capable of measuring three-axis accelerations, three orientation angles, and three-axis angular rates; they were used to measure mass center accelerations as well as the $m_{b 1}$ and $m_{b 2}$ roll angles. The angular position sensor used to measure the $\theta_{d}$ angle consisted of a potential meter.

IPM mass center accelerations and angle $\theta_{d}$ (input for simulating a driver's tilting motion) were used with (6)-(13) and (F1)-(F19) to obtain ground force data, which are necessary for performing simulations. Acceleration and $\theta_{d}$ signals were filtered using a $3 \mathrm{~Hz}$ low-pass filter to compensate for vehicle vibration prior to being fed to the model. Model parameters are shown in Tables I and III-VIII. The initial orientation angles of body-fixed coordinates with respect to global coordinates were set at zero. Comparative data between the model and IPM are shown as follows: $m_{b 1}$ roll angles at each speed without tilting motion in Fig. 19, $m_{b 1}$ roll angles at each speed with tilting motion in Fig. 20, $m_{b 2}$ roll angles at each speed without tilting motion in Fig. 21, and $m_{b 2}$ roll angles at each speed with tilting motion in Fig. 22.

As noted in the figures, simulation results were very close to those from the actual tests. Possible reasons for differences between the two are: 1) joint frictions were ignored in the model; 2) road roughness violated the force input assumption from 
TABLE II

Positions of Vehicle AND Model Mass Centers

\begin{tabular}{c||c|c}
\hline & The real vehicle & The model \\
\hline \hline $\begin{array}{l}\text { Position of mass } \\
\text { center }[\mathrm{x}, \mathrm{y}](\mathrm{m})\end{array}$ & {$[0,0.54]$} & {$[0,0.5488]$} \\
\hline
\end{tabular}

TABLE III

INITIAL MASS CENTER Positions, MASS, AND MOMENTS OF INERTIA OF FIG. 7 BODIES

\begin{tabular}{c||c|c|c}
\hline Body & $\begin{array}{c}\text { Mass center position } \\
{[\mathrm{x}, \mathrm{y}](\mathrm{m})}\end{array}$ & $\begin{array}{c}\text { Mass } \\
(\mathrm{kg})\end{array}$ & Moment of inertia $\left(\mathrm{kg} \cdot \mathrm{m}^{2}\right)$ \\
\hline \hline$m_{b 1}$ & {$[0,0.3799]$} & 73.7 & 8.4096 \\
\hline$m_{b 2}$ & {$[0,0.7908]$} & 141.3 & 9.3075 \\
\hline$m_{b 3}$ & {$[0,0.3808]$} & 2.55 & 0.1356 \\
\hline$m_{b 4}$ & {$[-0.3478,0.2009]$} & 6.34 & 0.0400 \\
\hline$m_{b 5}$ & {$[-0.4385,0.2205]$} & 8.64 & 0.1052 \\
\hline$m_{b 6}$ & {$[0.3478,0.2009]$} & 6.34 & 0.0400 \\
\hline$m_{b 7}$ & {$[0.4385,0.2205]$} & 8.64 & 0.1052 \\
\hline$m_{b 8}$ & {$[0,0.1990]$} & 22.2 & 0.1498 \\
\hline
\end{tabular}

TABLE IV

Initial Relative Positions of JoInTS to MASs CEnTERs of CONNECTING BODIES IN FIG. 7

\begin{tabular}{c||c|c}
\hline $\begin{array}{c}\text { The } \\
\text { joint }\end{array}$ & $\begin{array}{c}\text { Position on body-i } \\
{[\mathrm{x}, \mathrm{y}](\mathrm{m})}\end{array}$ & $\begin{array}{c}\text { Position on body-j} \\
{[\mathrm{x}, \mathrm{y}](\mathrm{m})}\end{array}$ \\
\hline \hline$J_{1}$ & {$[0,-0.2152]$} & {$[0,-0.6261]$} \\
\hline$J_{2}$ & {$[-0.4234,-0.2152]$} & {$[-0.0756,-0.0362]$} \\
\hline$J_{3}$ & {$[0.4234,-0.2152]$} & {$[0.0756,-0.0362]$} \\
\hline$J_{4}$ & {$[0,-0.4256]$} & {$[0,-0.0156]$} \\
\hline$J_{5}$ & {$[-0.3900,0.0229]$} & {$[-0.0422,0.2028]$} \\
\hline$J_{6}$ & {$[0.3900,0.0229]$} & {$[0.0422,0.2028]$} \\
\hline$J_{7}$ & {$[0.0074,-0.0337]$} & {$[0.0414,-0.0728]$} \\
\hline$J_{8}$ & {$[0.0074,0.1708]$} & {$[0.0414,0.1317]$} \\
\hline$J_{9}$ & {$[-0.0074,-0.0337]$} & {$[-0.0414,-0.0728]$} \\
\hline$J_{10}$ & {$[-0.0074,0.1708]$} & {$[-0.0414,0.1317]$} \\
\hline$J_{11}$ & {$[0,-0.5918]$} & {$[0,0]$} \\
\hline & & \\
\hline
\end{tabular}

TABLE V

ORIGINAL LENGTHS, SPRING CONSTANTS, AND DAMPING COEFICIENTS OF SUSPENSIONS IN FIG. 7

\begin{tabular}{c||c|c|c}
\hline Body & $\begin{array}{c}\text { Original } \\
\text { length }(\mathrm{m})\end{array}$ & $\begin{array}{l}\text { Spring constant } \\
(\mathrm{N} / \mathrm{m})\end{array}$ & $\begin{array}{l}\text { Damping coefficient } \\
(\mathrm{N} \cdot \mathrm{sec} / \mathrm{m})\end{array}$ \\
\hline \hline$S_{1}$ & 0.606 & $3.5012 \times 10^{4}$ & $2.694 \times 10^{3}$ \\
\hline$S_{2}$ & 0.254 & $3.7300 \times 10^{4}$ & $4.499 \times 10^{3}$ \\
\hline$S_{3}$ & 0.254 & $3.7300 \times 10^{4}$ & $4.499 \times 10^{3}$ \\
\hline
\end{tabular}

TABLE VI

Original Tire Section Heights, SPRING Constants, AND DAMPING COEFFICIENTS OF TIRES IN FIG. 7

\begin{tabular}{c||c|l|l}
\hline Body & $\begin{array}{c}\text { Original tire } \\
\text { section height }(\mathrm{m})\end{array}$ & $\begin{array}{l}\text { Spring } \\
\text { constant }(\mathrm{N} / \mathrm{m})\end{array}$ & $\begin{array}{l}\text { Damping } \\
\text { coefficient } \\
(\mathrm{N} \cdot \mathrm{sec} / \mathrm{m})\end{array}$ \\
\hline \hline$W_{1}$ & 0.079 & $1.76560 \times 10^{5}$ & $9.78 \times 10^{2}$ \\
\hline$W_{2}$ & 0.102 & $1.11730 \times 10^{5}$ & $6.30 \times 10^{2}$ \\
\hline$W_{3}$ & 0.102 & $1.11730 \times 10^{5}$ & $6.30 \times 10^{2}$ \\
\hline
\end{tabular}

TABLE VII

InITIAL RELATIVE POSITIONS OF SUSPENSION SySTEMS TO CONNECTING BODIES IN FIG. 7

\begin{tabular}{c||c|c|c}
\hline Body & $\begin{array}{c}\text { Connecting bodies } \\
{[\text { body- } i, \text { body-j] }}\end{array}$ & $\begin{array}{c}\text { Position on } \\
\text { body- } i[\mathrm{x}, \mathrm{y}](\mathrm{m})\end{array}$ & $\begin{array}{c}\text { Position on } \\
\text { body- } j[\mathrm{x}, \mathrm{y}](\mathrm{m})\end{array}$ \\
\hline \hline$S_{1}$ & {$\left[m_{b 2}, m_{b 8}\right]$} & {$[0,0]$} & {$[0,0]$} \\
\hline$S_{2}$ & {$\left[m_{b 4}, m_{b 5}\right]$} & {$[-0.0074,0.1837]$} & {$[0.0414,-0.0728]$} \\
\hline$S_{3}$ & {$\left[m_{b 6}, m_{b 7}\right]$} & {$[0.0074,0.1837]$} & {$[-0.0414,-0.0728]$} \\
\hline
\end{tabular}

TABLE VIII

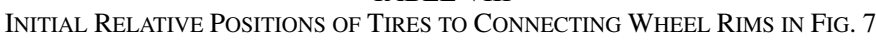

\begin{tabular}{c||c|c}
\hline Body & Wheel rims & $\begin{array}{l}\text { Position on wheel rim } \\
{[\mathrm{x}, \mathrm{y}](\mathrm{m})}\end{array}$ \\
\hline \hline$W_{1}$ & $m_{b 8}$ & {$[0,-0.1313]$} \\
\hline$W_{2}$ & $m_{b 5}$ & {$[-0.0365,-0.1285]$} \\
\hline$W_{3}$ & $m_{b 7}$ & {$[0.0365,-0.1285]$} \\
\hline
\end{tabular}
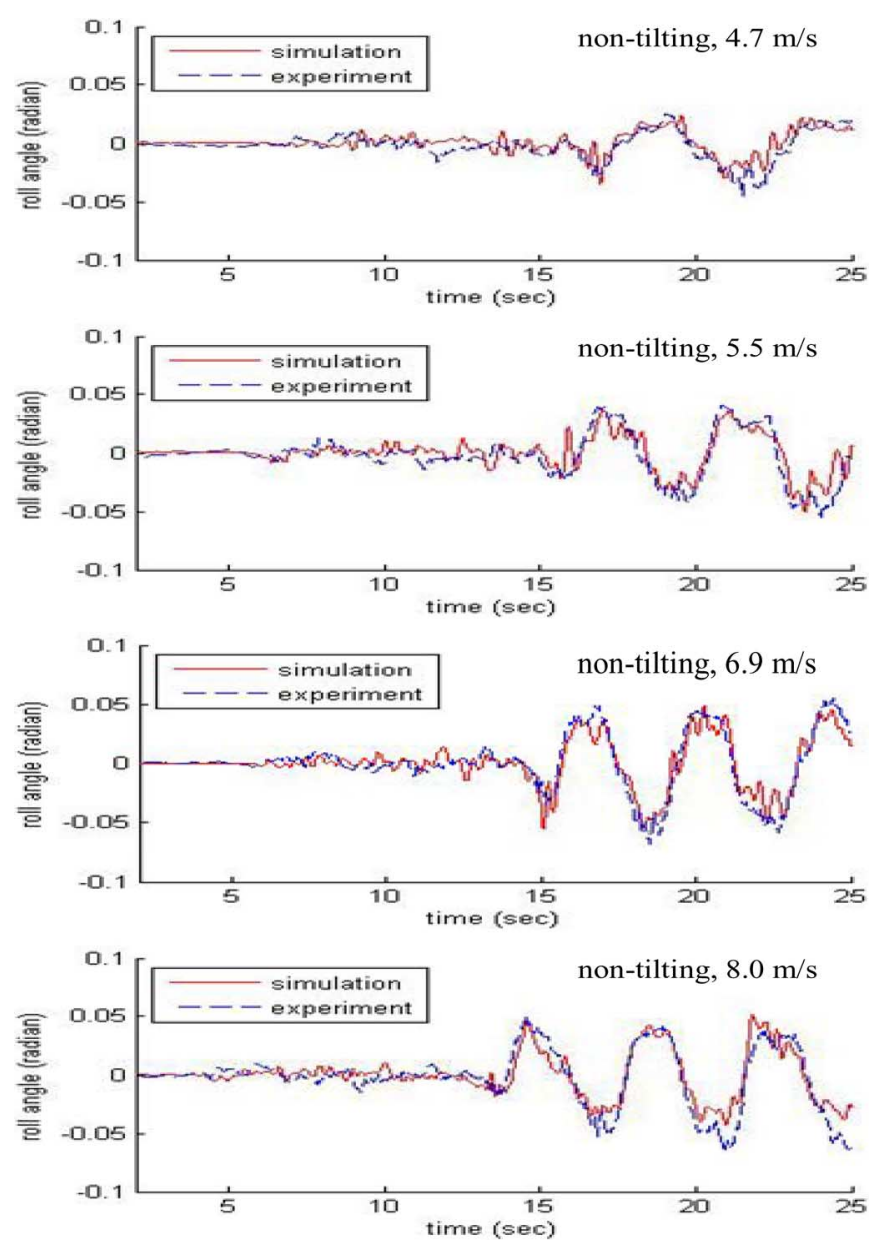

Fig. 19. Roll angle of $m_{b 1}$ for model and vehicle without tilting.

(F5)-(F19); and/or 3) sensor signals were inaccurate. Still, the combined results suggest that the model did accurately approximate the roll plane motion of the vehicle. We therefore suggest that the model can be used to simulate hazardous driving conditions. 

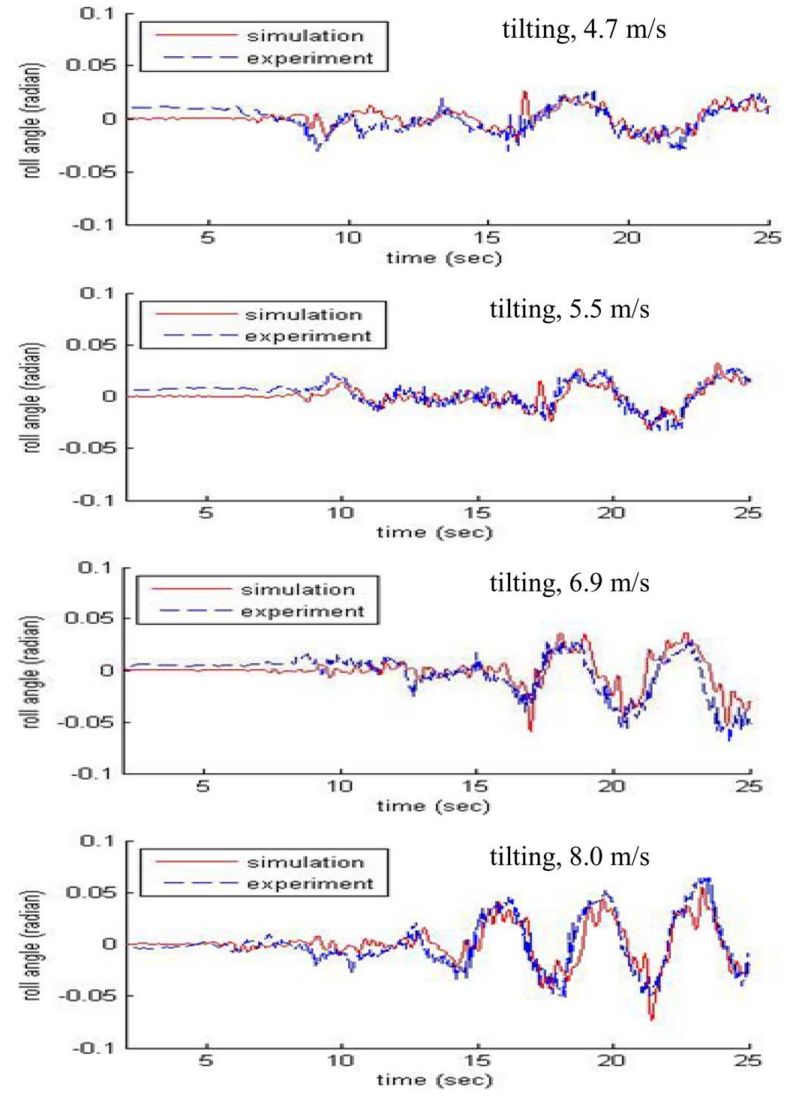

Fig. 20. Roll angle of $m_{b 1}$ for model and vehicle with tilting.
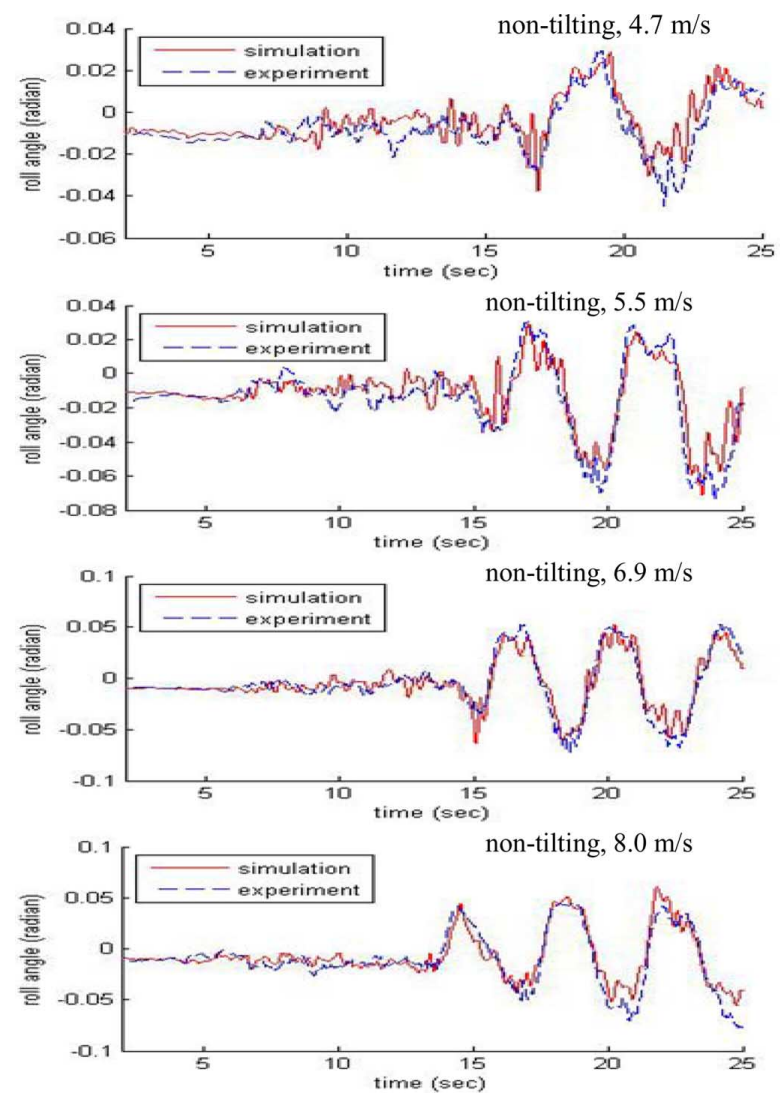

Fig. 21. Roll angle of $m_{b 2}$ for model and vehicle without tilting.
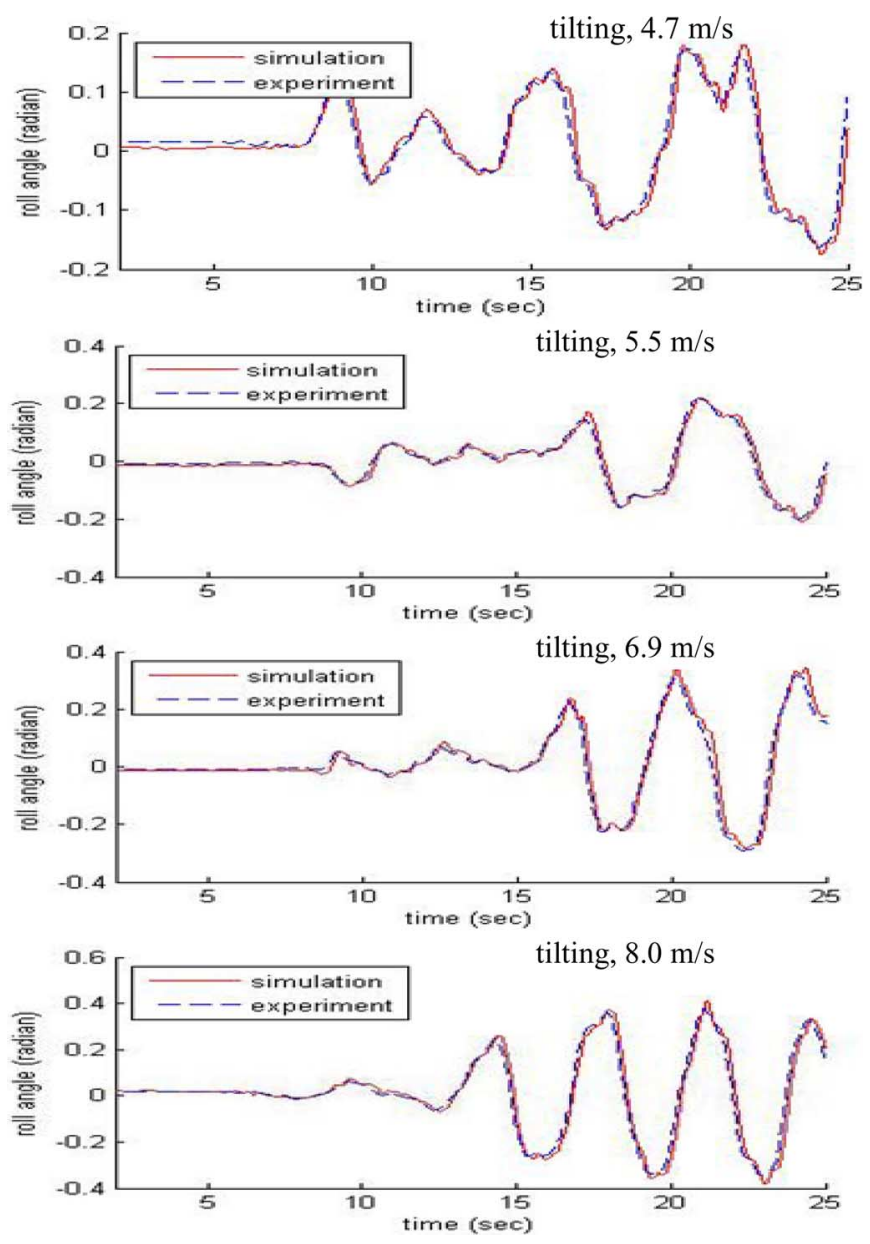

Fig. 22. Roll angle of $m_{b 2}$ for model and vehicle with tilting.
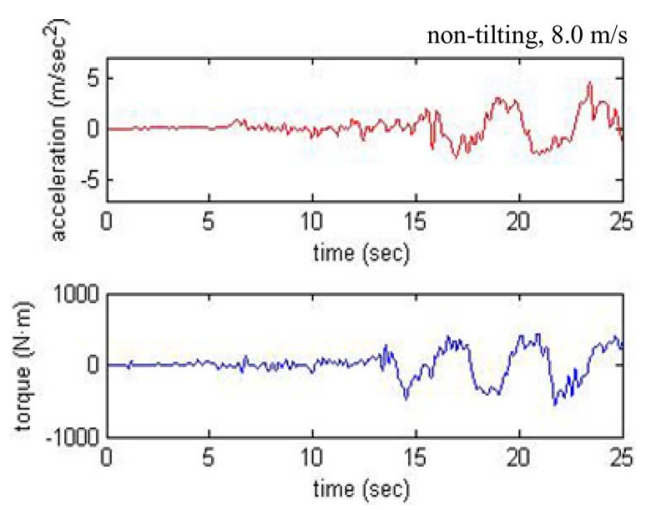

Fig. 23. Torque acting on $m_{b 1}$ at constraint $J_{r, d}$ for model without tilting.

\section{MODEL APPLICATIONS}

\section{A. Controller Design}

Model-derived data for the $x$-direction acceleration of $m_{b 2}$ and torque at constraint $J_{r, d}$ acting on $m_{b 1}$ during the simulated slalom test at a speed of $8.0 \mathrm{~m} / \mathrm{s}$ are shown in Figs. 23 (without tilting) and 24 (with tilting). The results indicate a lower torque, and therefore, greater stability, for the simulated tilting model. In other words, the results suggest that 

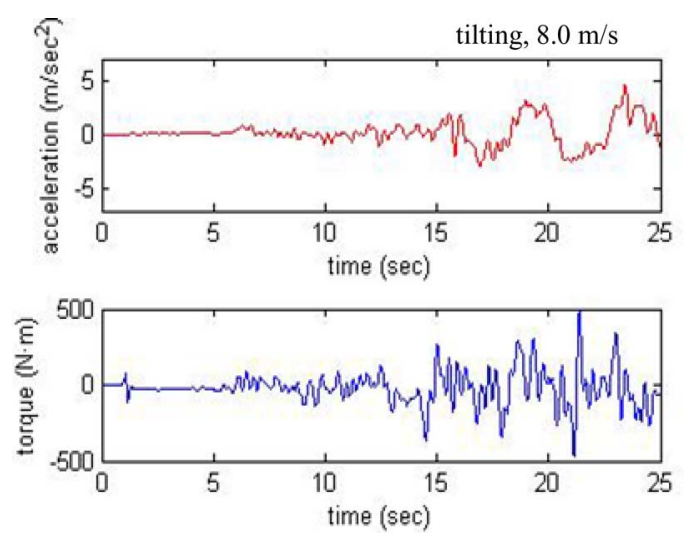

Fig. 24. Torque acting on $m_{b 1}$ at constraint $J_{r, d}$ for model with tilting.
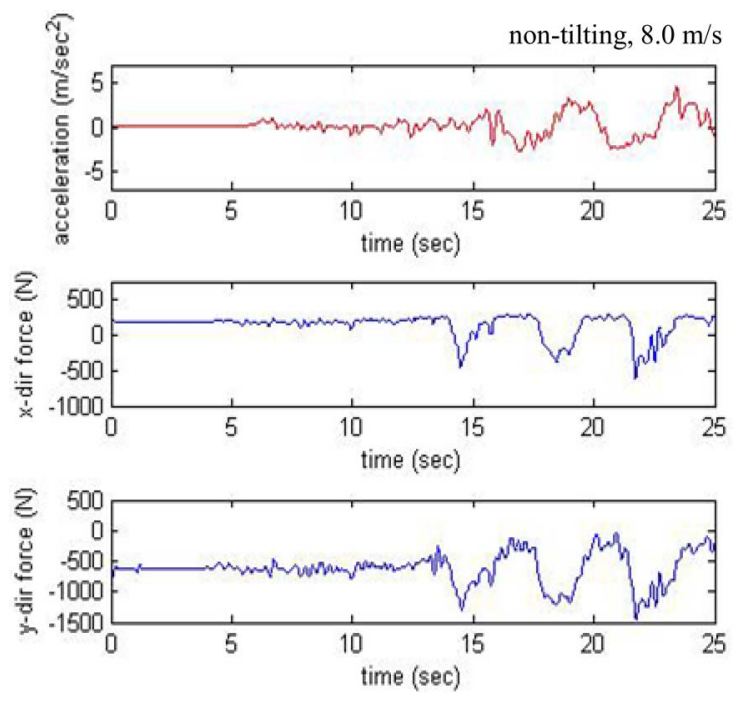

Fig. 25. Reaction forces acting on $m_{b 1}$ at joint $J_{2}$ for model without tilting.
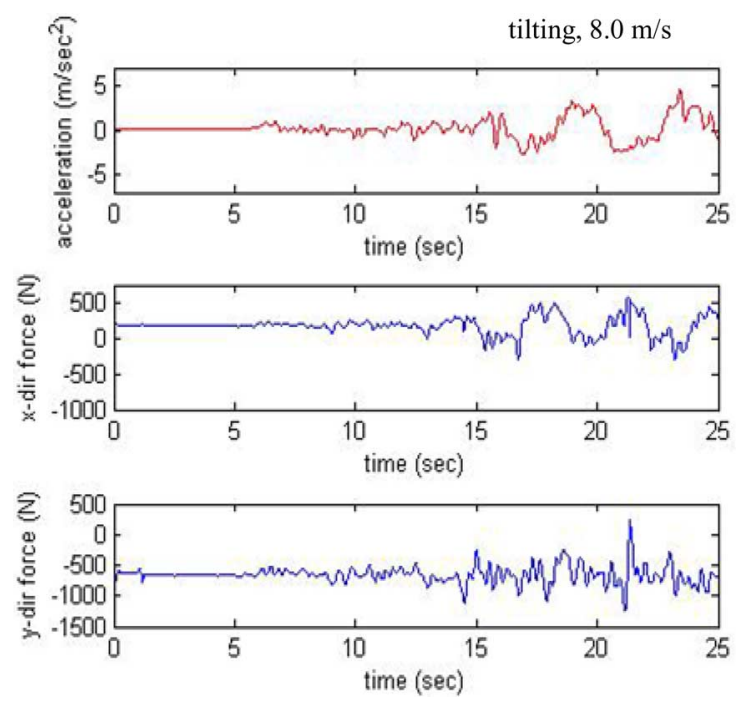

Fig. 26. Reaction forces acting on $m_{b 1}$ at joint $J_{2}$ for model with tilting. when an extreme tilting motion is executed, the vehicle still maintains a low torque. This conclusion agrees with Kidane et al.'s [1] results from a project in which they designed a tilt angle controller to minimize the aforementioned torque for driver comfort.

\section{B. Mechanical System Design}

Model-derived data for the $x$-direction acceleration of $m_{b 2}$ and reaction forces acting at joint $J_{2}$ on $m_{b 1}$ during the simulated slalom test at a speed of $8.0 \mathrm{~m} / \mathrm{s}$ are shown in Figs. 25 (without tilting) and 26 (with tilting); " $x$-dir force" and " $y$-dir force" denote $x$ - and $y$-direction reaction forces. A comparison of the two figures indicates that the reaction forces for the model with tilting were more stable, and that reaction forces for all joints can be obtained for either tilting or nontilting motions. Accordingly, we believe that our NTV model is a valid tool for vehicle design tasks involving joint strength and that it can extend to other mechanical systems.

\section{CONCLUSION}

In this paper, we described our proposal for a multibody NTV model with four wheels arranged in a diamond shape. This model was used to derive a tire force model for multibody systems. We also discussed our proposed method for obtaining approximate forces from the ground using two acceleration sensors and one angular position sensor, and compared data from a multibody model simulation and an actual slalom test using an IPM prototype. Results indicate that the multibody model is capable of simulating IPM vehicle driving characteristics, and that the resulting information can be used to design a tilting angle controller with driver comfort as a priority. Our next task is to build a tilting angle controller after verifying a design using the model described in this paper.

\section{APPENDIX A}

Figs. 3 and 4 notations:

$\theta_{b} \quad$ Angle between vertical axis of body and normal direction of ground.

$\theta_{w} \quad$ Wheel camber angle.

$M_{c} \quad$ Chassis mass center. Chassis mass is $m_{c}$.

$M \quad$ Vehicle mass center. Vehicle mass is $m$.

$M_{b} \quad$ Non-chassis mass center. Non-chassis mass is $m_{b}$.

$t \quad$ Half wheel track.

$h_{b} \quad$ Distance between $M_{b}$ and revolute joint $J$.

$h_{c} \quad$ Distance between $M_{c}$ and revolute joint $J$.

$h_{w}$ Height from wheel center to ground in static situation.

$h_{c w} \quad$ Height from wheel center to revolute joint $J$ in static situation.

$x_{m} \quad$ Distance in $x$-direction from $M$ to bottom of right wheel.

$y_{m} \quad$ Distance in $y$-direction from $M$ to bottom of right wheel.

$a_{l} \quad$ Virtual centrifugal acceleration according to the assumption given in Section II-B.

$g \quad$ Gravity acceleration. 
$F_{y 1}, F_{y 2} \quad$ Normal forces acting on the two side wheels.

$F_{x 1}, F_{x 2} \quad$ Lateral forces acting on the two side wheels.

Equations (A1)-(A11), where (A4) and (A8) are as set at the bottom of this page, can be obtained from fundamental mechanics:

$$
\begin{gathered}
m=m_{b}+m_{c} \\
m_{b}: m_{c}=e: f \quad e+f=1 \quad e>0, \quad f>0 \\
x_{m}=\frac{\left[e\left(h_{w} \sin \theta_{w}+t+h_{b} \sin \theta_{b}\right)+f\left(h_{w} \sin \theta_{w}+t\right)\right]}{(e+f)} \\
\sum F x=0 \quad F_{x 1}+F_{x 2}=m a_{l} \\
\sum F y=0 \quad F_{y 1}+F_{y 2}=m g \\
\sum M=0 \quad m a_{l} y_{m}+2 F_{y 1} t=m g x_{m} \\
a_{l}=\frac{\left(m g x_{m}-2 F_{y 1} t\right)}{m y_{m}} .
\end{gathered}
$$

If rollover just happened $F_{y 1}=0$, then

$$
\begin{aligned}
& \left(\frac{a_{l}}{g}\right)_{\text {half-car-tilt }, \theta_{w}=0} \\
& \quad=\frac{\left[e\left(t+h_{b} \sin \theta_{b}\right)+f t\right]}{\left[e\left(h_{w}-h_{c w}+h_{b} \cos \theta_{b}\right)+f\left(h_{w}-h_{c w}+h_{c}\right)\right]} \\
& \left(\frac{a_{l}}{g}\right)_{\text {nontilting, } \theta_{w}=0, \theta_{b}=0} \\
& =\frac{t}{\left[e\left(h_{w}-h_{c w}+h_{b}\right)+f\left(h_{w}-h_{c w}+h_{c}\right)\right]} .
\end{aligned}
$$

If tilts to the left side, $0<\theta_{w}<1 / 2 \pi$ and $0<\theta_{b}<1 / 2 \pi$. Then,

$$
\begin{aligned}
\left(\frac{a_{l}}{g}\right)_{\text {whole-car-tilt }} & >\left(\frac{a_{l}}{g}\right)_{\text {half-car-tilt, } \theta_{w}=0} \\
& >\left(\frac{a_{l}}{g}\right)_{\text {nontilting, } \theta_{w}=0, \theta_{b}=0} .
\end{aligned} .
$$

\section{APPENDIX B}

In Fig. 6, numbers in brackets indicate the following body parts.

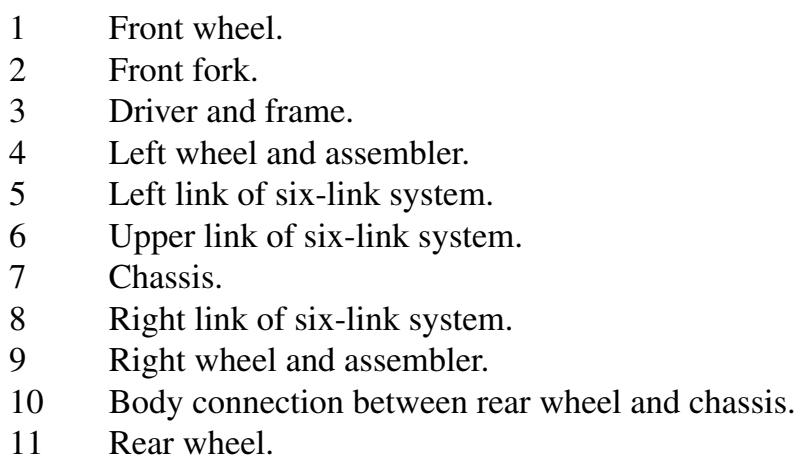

Fig. 7 notations are the following.

$m_{b 1} \quad$ Body 7 in Fig. 6.

$m_{b 2}$ Combination of bodies 2, 3, and 10 in Fig. 6 . The combination of bodies means that the mass value represents a summation of the corresponding bodies. New mass center positions and recalculated moments of inertia with respect to the new mass center must be determined. In addition, the combination coordinates need to be redefined.

$m_{b 3} \quad$ Body 6 in Fig. 6.

$m_{b 4} \quad$ Body 8 in Fig. 6.

$m_{b 5} \quad$ Body 9 in Fig. 6.

$m_{b 6} \quad$ Body 5 in Fig. 6.

$m_{b 7} \quad$ Body 4 in Fig. 6.

$m_{b 8} \quad$ Combination of bodies 1 and 11 in Fig. 6.

$S_{1} \quad$ Front and rear suspension system, consisting of springs and dampers.

$S_{2} \quad$ Right side suspension system.

$S_{3} \quad$ Left side suspension system.

$W_{1} \quad$ Front and rear tire force model, consisting of springs and dampers.

$W_{2} \quad$ Right side tire force model.

$W_{3} \quad$ Left side tire force model.

$F_{x c} \quad$ Force from ground exerted on $W_{1}$ in $x$-direction.

$F_{x s r} \quad$ Force from ground exerted on $W_{2}$ in $x$-direction.

$F_{x s l} \quad$ Force from ground exerted on $W_{3}$ in $x$-direction.

$J_{r, d} \quad$ Relative revolute driving constraint between $m_{b 1}$ and $m_{b 2}$ for simulating a driver's tilting motion.

Note:

1) $J_{1}, J_{2}, J_{3}, J_{4}, J_{5}, J_{6}, J_{7}, J_{8}, J_{9}, J_{10}$, and $J_{11}$ are joints. Joint type, number of constraint equations, and connecting bodies are shown in Table I.

$$
y_{m}=\frac{\left[e\left(\left(h_{w}-h_{c w}\right) \cos \theta_{w}+h_{b} \cos \theta_{b}\right)+f\left(\left(h_{w}-h_{c w}\right) \cos \theta_{w}+h_{c}\right)\right]}{(e+f)}
$$

$$
\begin{aligned}
\left(\frac{a_{l}}{g}\right)_{\text {whole-car-tilt }} & =\frac{x_{m}}{y_{m}} \\
& =\frac{\left[e\left(h_{w} \sin \theta_{w}+t+h_{b} \sin \theta_{b}\right)+f\left(h_{w} \sin \theta_{w}+t\right)\right]}{\left[e\left(\left(h_{w}-h_{c w}\right) \cos \theta_{w}+h_{b} \cos \theta_{b}\right)+f\left(\left(h_{w}-h_{c w}\right) \cos \theta_{w}+h_{c}\right)\right]}
\end{aligned}
$$




\section{APPENDIX C}

Fig. 8 is an illustration of the multibody system coordinates. Definitions are as follows.

$x-y$ coordinate Fixed on reference point as a global coordinate.

$\xi_{i} \eta_{i}$ coordinate Body-fixed coordinate on body $i$. The original point of $\xi_{i} \eta_{i}$ axes is $O_{i}$.

$\Psi_{i} \quad$ Orientation angle of $\xi_{i} \eta_{i}$ coordinate with respect to global coordinate.

vector $\boldsymbol{r}_{\boldsymbol{i}} \quad$ Position vector of point $O_{i}$ with respect to $x-y$ coordinate system. As shown in (C1), $\boldsymbol{r}_{\boldsymbol{i}}$ components are $x_{i}$ and $y_{i}$.

$P_{i} \quad$ Arbitrary point on body $i$ located from point $O_{i}$ by the $s_{\boldsymbol{i}, \boldsymbol{p}}$ vector with respect to $x y$ coordinate system. $P_{i}$ coordinates in relation to the $\xi_{i} \eta_{i}$ coordinate system are $\xi_{i, p}$ and $\eta_{i, p}$.

$\boldsymbol{s}_{\boldsymbol{i}, \boldsymbol{p}}^{\prime} \quad$ Body-fixed components of vector $\boldsymbol{s}_{\boldsymbol{i}, \boldsymbol{p}}$ shown in (C2). Since $P_{i}$ is a fixed point on body $\boldsymbol{i}, \boldsymbol{s}_{\boldsymbol{i}, \boldsymbol{p}}^{\prime}$ components are constants, and $\boldsymbol{s}_{\boldsymbol{i}, \boldsymbol{p}}^{\prime}$ is a constant vector. $P_{i}$ can also be located via global coordinate, as shown in (C6).

$\boldsymbol{r}_{\boldsymbol{i}, \boldsymbol{p}} \quad$ Global coordinates of $P_{i}$. Its components, $x_{i, p}$ and $y_{i, p}$, can be computed using (C3) and (C4), respectively.

Notes:

1) Defined coordinates can be used to obtain the transformation matrix $\boldsymbol{A}_{\boldsymbol{i}}$ shown in (C5).

2) The relationship between the global and body-fixed coordinates of $P_{i}$ is shown in (C6). Accordingly, $\boldsymbol{s}_{\boldsymbol{i}, \boldsymbol{p}}$ in (C6) can be computed using (C7).

3) $s_{i, p x}$ and $s_{i, p y}$ are $s_{i, p}$ components.

4) $P_{i}$ velocity can be further derived using a time derivative of (C6), which yields (C8)

$$
\begin{aligned}
& \boldsymbol{r}_{\boldsymbol{i}}=\left[\begin{array}{ll}
x_{i} & y_{i}
\end{array}\right]^{T} \\
& \boldsymbol{s}_{\boldsymbol{i}, \boldsymbol{p}}^{\prime}=\left[\begin{array}{ll}
\xi_{i, p} & \eta_{i, p}
\end{array}\right]^{T} \\
& x_{i, p}=x_{i}+\xi_{i, p} \cos \Psi_{i}-\eta_{i, p} \sin \Psi_{i} \\
& y_{i, p}=y_{i}+\xi_{i, p} \sin \Psi_{i}+\eta_{i, p} \cos \Psi_{i} \\
& \boldsymbol{A}_{\boldsymbol{i}}=\left[\begin{array}{cc}
\cos \Psi_{i} & -\sin \Psi_{i} \\
\sin \Psi_{i} & \cos \Psi_{i}
\end{array}\right] \\
& \boldsymbol{r}_{\boldsymbol{i}, \boldsymbol{p}}=\left[\begin{array}{ll}
x_{i, p} & y_{i, p}
\end{array}\right]^{T}=\boldsymbol{r}_{i}+\boldsymbol{A}_{\boldsymbol{i}} \boldsymbol{s}_{\boldsymbol{i}, \boldsymbol{p}}^{\prime} \\
& \boldsymbol{s}_{\boldsymbol{i}, \boldsymbol{p}}=\boldsymbol{A}_{\boldsymbol{i}} \boldsymbol{s}_{\boldsymbol{i}, \boldsymbol{p}}^{\prime}=\left[\begin{array}{ll}
s_{i, p x} & s_{i, p y}
\end{array}\right]^{T} \\
& \dot{\boldsymbol{r}}_{\boldsymbol{i}, \boldsymbol{p}}=\left[\begin{array}{ll}
\dot{x}_{i, p} & \dot{y}_{i, p}
\end{array}\right]^{T}=\dot{\boldsymbol{r}}_{\boldsymbol{i}}+\dot{\boldsymbol{s}}_{\boldsymbol{i}, \boldsymbol{p}}=\dot{\boldsymbol{r}}_{\boldsymbol{i}}+\dot{\Psi}_{i} \boldsymbol{B}_{\boldsymbol{i}} \boldsymbol{s}_{\boldsymbol{i}, \boldsymbol{p}}^{\prime}(\mathrm{C} 8) \\
& \boldsymbol{B}_{\boldsymbol{i}}=\left[\begin{array}{cc}
-\sin \Psi_{i} & -\cos \Psi_{i} \\
\cos \Psi_{i} & -\sin \Psi_{i}
\end{array}\right] \text {. }
\end{aligned}
$$

\section{APPENDIX D}

$F_{j, y s} \quad$ Force exerted on body $j$ from spring.

$F_{j, y d}$ Force exerted on body $j$ from damper. $y_{j, c} \quad$ Point $C_{j}$ component with respect to $y$-axis.

$C_{t} \quad$ Damping coefficient.

$K_{t} \quad$ Spring constant.

$l_{o} \quad$ Original distance between $P_{j}$ and $C_{j}$.

$r_{c j} \quad$ Position vector of point $C_{j}$ with respect to global coordinate. It can be computed using (D4).

$s_{j, c} \quad$ Location of point $C_{j}$ from point $O_{j}$ with respect to global coordinate. It can be computed using (D5).

Notes:

1) In Fig. 9, the position vector components of point $C_{j}$ with respect to the $x y$-axes can be calculated if the road profile is given. Equivalent spring and damper forces can be computed using (D1) and (D2).

2) As per (D3), $F_{j, x}$ is equal to $F_{c j, x}$, and $F_{j, y}$ is the summation of $F_{j, y s}$ and $F_{j, y d}$. However, according to the dynamic properties of tires, if $F_{j, y s} \leq 0, F_{j, x}$ and $F_{j, y}$ are also 0 . Also, if $F_{j, y d} \leq 0, F_{j, y d}=0$.

3) To obtain the torque value exerted on the wheel rim from the tire, the location vector of point $C_{j}$ from point $O_{j}$ must be obtained.

4) As shown in (D6), an operator tilde was added to compute the torque on bodyj in matrix form. Torque $N_{j}$ can therefore be derived as shown in (D7).

$$
\begin{aligned}
& F_{j, y s}=-K_{t}\left(y_{j, p}-y_{j, c}-l_{o}\right) \\
& F_{j, y d}=-C_{t}\left(\dot{y}_{j, p}-\dot{y}_{j, c}\right) \\
& \text { If } F_{j, y s} \leq 0, F_{j, y}, F_{j, x} \text { and } N_{j} \text { are zero, } \\
& \text { else } \\
& F_{j, y}=F_{j, y s}+F_{j, y d}\left(\text { if } F_{j, y d}<0, F_{j, y d}=0\right) \\
& F_{j, x}=F_{c j, x} \\
& \boldsymbol{r}_{c j}=\left[\begin{array}{ll}
x_{j, p} & y_{c j}
\end{array}\right]^{T} \\
& \boldsymbol{s}_{j, c}=\boldsymbol{r}_{c j}-\boldsymbol{r}_{j}=\left[\begin{array}{ll}
s_{j, p x} & \left(y_{c j}-y_{j}\right)
\end{array}\right]^{T} \\
& \text { If } \boldsymbol{a}=\left[\begin{array}{ll}
a_{x} & a_{y}
\end{array}\right]^{T}, \quad \text { then } \widetilde{\boldsymbol{a}}=\left[\begin{array}{ll}
-a_{y} & a_{x}
\end{array}\right] \\
& N_{j}=\widetilde{\boldsymbol{s}_{j, c}}\left[\begin{array}{ll}
\boldsymbol{F}_{j, x} & \boldsymbol{F}_{j, y}
\end{array}\right]^{T} \text {. }
\end{aligned}
$$

\section{APPENDIX E}

Notations for Figs. 12-14 and (6)-(13) are the following.

$\theta_{\mathrm{sl}} \quad$ Camber angle of left side wheel.

$\theta_{\mathrm{sr}} \quad$ Camber angle of right side wheel.

$\varphi \quad$ Chassis roll angle.

$\theta_{d} \quad$ Angle between $m_{b 2}$ vertical axis and $m_{b 1}$ horizontal axis.

$\theta_{m} \quad$ Angle between line from $M$ to joint $J_{1}$ (see Fig. 7) and normal ground direction.

$L_{c j, x}$ Component of $M$ location from joint $J_{1}$ in $x$-direction.

$L_{c j, y}$ Component of $M$ location from joint $J_{1}$ in $y$-direction.

$l_{b} \quad$ Distance between $M_{b}$ and joint $J_{1}$.

$l_{c h} \quad$ Distance between $M_{c}$ and joint $J_{1}$.

$l_{m o} \quad$ Distance between $M$ and joint $J_{1}$. 


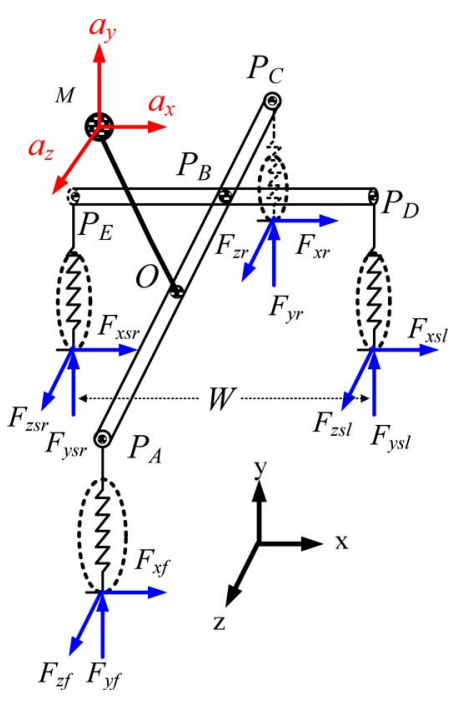

Fig. 27. Forces exerted on IPM from the ground.

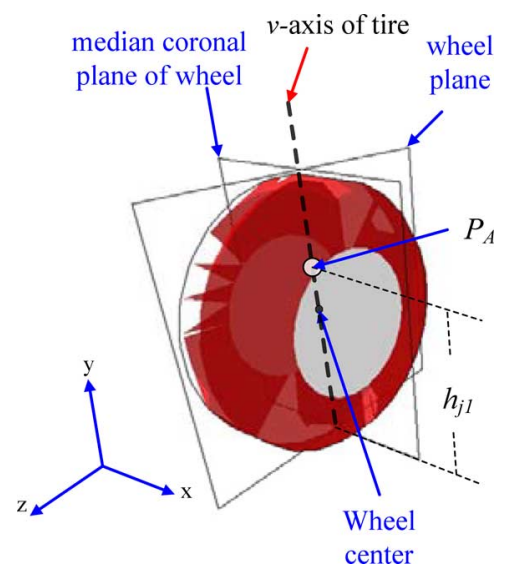

Fig. 28. Definition of wheel $v$-axis.

\section{APPENDIX F}

Notations for Figs. 27-29 and (F1)-(F19) are the following.

$O$

$v$-axis

$h_{j 1}$

$P_{A}$

$P_{C} \quad$ Rear end point of cross, similar to $P_{A}$ end point.

$P_{D} \quad$ Left end point of cross, similar to $P_{A}$ end point.

$P_{E} \quad$ Right end point of cross, similar to $P_{A}$ end point.

$P_{B} \quad$ Cross intersection.

$l_{a} \quad$ Distance between points $P_{A}$ and $O$.

$l_{o b} \quad$ Distance between points $O$ and $P_{B}$.

$l_{c} \quad$ Distance between points $P_{B}$ and $P_{C}$.

$w \quad$ Distance between points $P_{D}$ and $P_{E}$.

$\mathrm{O}_{2} \quad$ Projection point of point $O$ on ground.

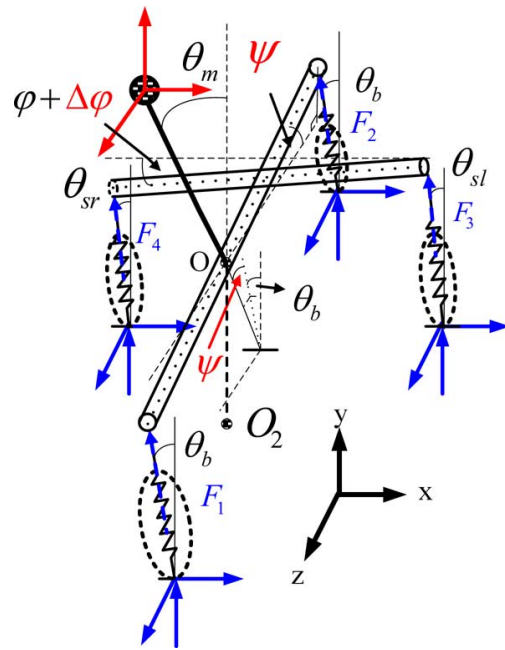

Fig. 29. Spring deflection caused by forces from ground and kinematic motion.

$\Delta z \quad$ Vertical displacement of $O$.

$\psi \quad$ Cross pitch angle by spring deflection.

$\Delta \varphi \quad$ Cross roll angle by spring deflection.

$\psi_{f}$ and $\psi_{r} \quad$ Respective assembled angles of front and rear suspension systems rotated around $x$-axis.

$a_{x}, a_{y}, \quad$ Respective measured accelerations in $x-, y-$, and and $a_{z}$ $z$-directions.

$F_{x f} \quad x$-direction force from front tire ground.

$F_{x r} \quad x$-direction force from rear tire ground.

$F_{x s l} \quad x$-direction force from left side tire ground.

$F_{x s r} \quad x$-direction force from right side tire ground.

$F_{y f} \quad y$-direction force from front tire ground.

$F_{y r} \quad y$-direction force from rear tire ground.

$F_{y s l} \quad y$-direction force from left side tire ground.

$F_{y s r} \quad y$-direction force from right side tire ground.

$F_{z f} \quad z$-direction force from front tire ground.

$F_{z r} \quad z$-direction force from rear tire ground.

$F_{z s l} \quad z$-direction force from left side tire ground.

$F_{z s r} \quad z$-direction force from right side tire ground.

$F_{1} \quad$ Front equivalent spring internal force.

$F_{2} \quad$ Rear equivalent spring internal force.

$F_{3} \quad$ Left side equivalent spring internal force.

$F_{4} \quad$ Right side equivalent spring internal force.

$k_{f, v} \quad$ Front equivalent spring vertical spring constant.

$k_{r, v} \quad$ Rear equivalent spring vertical spring constant.

$k_{s l, v} \quad$ Left side equivalent spring vertical spring constant.

$k_{s r, v} \quad$ Right side equivalent spring vertical spring constant.

$k_{f} \quad$ Front suspension system spring constant.

$k_{r} \quad$ Rear suspension system spring constant.

$k_{s l} \quad$ Left side suspension system spring constant.

$k_{s r} \quad$ Right side suspension system spring constant.

$k_{t f} \quad$ Front tire vertical spring constant.

$k_{t r} \quad$ Rear tire vertical spring constant.

$k_{t s l} \quad$ Left side tire vertical spring constant.

$k_{t s r} \quad$ Right side tire vertical spring constant. 
Fig. 27 illustrates actual external forces acting on the IPM vehicle prior to deflection, assuming steady-state cornering on a flat road. Thus, all steady-state maneuvering motions can be treated as special cases of steady-state cornering. Angular acceleration and rotational wheel motion are disregarded due to their insignificant values.

Assuming that actual motions can be divided into fragments of steady-state motion, numerical simulations can be used to calculate ground forces for each state. Due to its small variance, note that during the suspension and tire deflecting stages, the wheel-ground contact point is assumed as being a fixed point.

For the sake of efficiency, the vehicle chassis was treated as a rigid body cross directly attached to four equivalent springs. Spring constants are equivalent to those for the corresponding suspensions and tires. The final constants for the four equivalent springs are derived using (F1)-(F4); the equations indicate that the spring constants change with the IPM mechanism angles. The cross in Fig. 7 is parallel to the $x-$ $z$ plane, with the same height as the $J_{1}$ joint. The cross was assumed as having no mass and no moment of inertia. $M$ (the IPM mass center) moves with $\theta_{m}$ and the suspension/tire deflection.

Fig. 29 is an equivalent cross with the deflection of equivalent springs via cornering. According to the mechanism, point $O$ is assumed as the rotation center of the pitch and roll motions caused by the deflection of the four springs. In a steady state, those deflections can be replaced by $\Delta z, \psi$, and $\Delta \varphi$. Furthermore, $F_{1}, F_{2}, F_{3}$, and $F_{4}$ represent overall forces from the ground acting on each individual spring direction, leading to (F5)-(F8). Next, (F9)-(F11) are derived using the force and torque equilibrium principle. Note that according to the dynamic property of tires, the normal forces cannot be negative. If a normal force is negative or zero, its value is reset as zero. Assuming normal operating conditions, friction forces from the ground will be proportional to the corresponding normal forces, and lead to (F12)-(F19). Fig. 15 contains a proposed method for calculating forces from the ground induced by the measured accelerations $a_{x}, a_{y}$, and $a_{z}$. Gravity is considered in $a_{y}$.

$$
\begin{aligned}
k_{f, v} & =\frac{k_{f} k_{t f}}{\left(k_{t f}+k_{f} \cos \theta_{b}\right)} \\
k_{r, v} & =\frac{k_{r} k_{t r}}{\left(k_{t r}+k_{r} \cos \theta_{b}\right)} \\
k_{s l, v} & =\frac{k_{s l} k_{t s l}}{\left(k_{t s l}+k_{s l} \cos \theta_{s l}\right)} \\
k_{s r, v} & =\frac{k_{s r} k_{t s r}}{\left(k_{t s r}+k_{s r} \cos \theta_{s r}\right)} \\
F_{1} & =F_{z f} \sin \psi_{f}-F_{x f} \cos \psi_{f} \sin \theta_{b}+F_{y f} \cos \psi_{f} \cos \theta_{b} \\
& =\frac{k_{f, v}\left(\Delta z+l_{a} \psi\right)}{\left(\cos \psi_{f} \cos \theta_{b}\right)} \\
F_{2} & =F_{z r} \sin \psi_{r}-F_{x r} \cos \psi_{r} \sin \theta_{b}+F_{y r} \cos \psi_{r} \cos \theta_{b} \\
& =\frac{k_{r, v}\left[\Delta z-\left(l_{o b}+l_{c}\right) \psi\right]}{\left(\cos \psi_{r} \cos \theta_{b}\right)}
\end{aligned}
$$

$$
\begin{aligned}
F_{3}= & -F_{x s l} \sin \theta_{s l}+F_{y s l} \cos \theta_{s l} \\
= & \frac{k_{s l, v}\left(\Delta z-l_{c} \psi-w \Delta \varphi / 2\right)}{\cos \theta_{s l}} \\
F_{4}= & -F_{x s r} \sin \theta_{s r}+F_{y s r} \cos \theta_{s r} \\
= & \frac{k_{s r, v}\left(\Delta z-l_{c} \psi+w \Delta \varphi / 2\right)}{\cos \theta_{s r}} \\
\sum F_{y}= & m a_{y} \\
F_{y f} & +F_{y r}+F_{y s l}+F_{y s r}-m a_{y}=0 \\
\sum M_{z, o 2}=0, \text { then } & \\
& \left.-\left(F_{y f}+F_{y r}+F_{y s l}+F_{y s r}\right) \tan \theta_{b}-m a_{x}\right] \Delta z \\
& +\left[-m a_{x} l_{m o} \sin \theta_{m}+m a_{y} l_{m o} \cos \theta_{m}\right] \Delta \varphi \\
& +\left[\left(F_{y f}+F_{y r}+F_{y s l}+F_{y s r}\right) h_{o} \sin \theta_{b}\right. \\
F_{x s r}= & \frac{F_{y s r} a_{x}}{a_{y}} . \\
F_{x s l}= & \frac{\left(F_{y s l}-F_{y s r}\right) w}{2}+m a_{x} h_{o} \cos \theta_{b} \\
& +m a_{x} l_{m o} \cos \theta_{m}+m a_{y} l_{m o} \sin \theta_{m}=0 \\
F_{x f}= & \frac{F_{y f} m a_{x}}{\left(m a_{y}\right)}=\frac{F_{y f} a_{x}}{a_{y}} \\
F_{z r}= & \frac{F_{y r} a_{z}}{a_{y}} \\
F_{z s l}= & \frac{F_{y s l} a_{z}}{a_{y}} \\
M_{x, o 2}=0 & \frac{F_{y s r} a_{z}}{a_{y}} \\
& m a_{z} \Delta z+m a_{y} l_{m o} \psi+\left(m a_{z} l_{m o} \sin \theta_{m}\right) \Delta \varphi \\
& +\left[-l_{a} F_{y f}+\left(l_{o b}+l_{c}\right) F_{y r}+l_{c}\left(F_{y s l}+F_{y s r}\right)\right] \\
& +\left[-m a_{z} h_{o} \cos \theta_{b}-m a_{z} l_{m o} \cos \theta_{m}\right]=0 \\
F_{y} & F_{y f} m a_{z} \\
& F_{y f} a_{z} \\
\left.a_{y}\right) &
\end{aligned}
$$

\section{ACKNOWLEDGMENT}

The authors would like to thank the IEEE/ASME TRANSACTIONS ON MECHATRONICS Technical Editor and anonymous reviewers for their valuable feedback. 


\section{REFERENCES}

[1] S. Kidane, L. Alexander, R. Rajamani, P. Starr, and M. Donath, "Control system design for full range operation of a narrow commuter vehicle," in Proc. ASME Int. Mech. Eng. Congr. Expo., Orlando, FL, Nov. 2005, pp. $123-142$.

[2] R. Rajamani, J. Gohl, L. Alexander, and P. Starr, "Dynamics of narrow tilting vehicles," Math. Comput. Model. Dyn. Syst., vol. 9, no. 2, pp. 209231, 2003.

[3] K. M. Kockelman and Y. Zhao, "Behavioral distinctions: The use of light-duty trucks and passenger cars," J. Transp. Statist., vol. 3, no. 3, pp. 47-60, 2000 [Online]. Available: http://www.bts.gov/publications/journal_of_transportation_and_statistics/volume_03_number_03/ paper_03/index.html

[4] T. D. Gillespie, Fundamentals of Vehicle Dynamics. Warrendale, PA: Society of Automotive Engineers, 1992.

[5] R. Hibbard and D. Karnopp, "Twenty-first century transportation system solutions: A new type of small, relatively tall and narrow active tilting commuter vehicle," Vehicle Syst. Dyn., vol. 25, pp. 321-347, 1996.

[6] R. S. Sharp, "The stability and control of pivot-framed tricycles," in Proc. Eighth IASVD Symp., Suppl. Vehicle Syst. Dyn., 1983, pp. 564-577.

[7] T. Sato and N. Kanno, "Tricycle with two fore wheels," U.S. Patent 4360 224, Nov. 23, 1982.

[8] K. Kawasaki, “Articulated tricycle,” U.S. Patent 4541 501, Sep. 17, 1985.

[9] H. Fujita, K. Honma, and M. Ogawa, "Body banking suspension apparatus for a vehicle," U.S. Patent 4632413, Dec. 30, 1986.

[10] P. E. Nikravesh, Computer-Aided Analysis of Mechanical Systems. Englewood Cliffs, NJ: Prentice-Hall, 1988.

[11] R. S. Sharp and D. J. N. Limebeer, "A motorcycle model for stability and control analysis," Multibody Syst. Dyn., vol. 6, no. 2, pp. 123-142, 2001.

[12] R. Isermann, "Modeling and design methodology for mechatronic systems," IEEE/ASME Trans. Mechatron., vol. 1, no. 1, pp. 16-28, Mar. 1996.

[13] K. Natarajan, S. Yu, and F. Karray, "Modeling and control design for a flexible-link manipulator," in Proc. Can. Conf. Electr. Comput. Eng., May 24-28, 1998, vol. 1, pp. 117-120.

[14] M. Tai, P. Hingwe, and M. Tomizuka, "Modeling and control of steering system of heavy vehicles for automated highway systems," IEEE/ASME Trans. Mechatron., vol. 9, no. 4, pp. 609-618, Dec. 2004.

[15] S. Tafazoli, C. W. de Silva, and P. D. Lawrence, "Tracking control of an electrohydraulic manipulator in the presence of friction," IEEE Trans. Control Syst. Technol., vol. 6, no. 3, pp. 401-411, May 1998.

[16] S. D. Wu, J. C. Chiou, and J. Y. Yang, "A new constraint stabilization technique for dynamic systems with nonholonomic constraints," J. Guid. Navigat., Dyn. Control, vol. 22, no. 3, pp. 497-499, 1999.

[17] J. C. Chiou, K. C. Park, and C. Farhat, "A natural partitioning scheme for parallel simulation of multibody systems," Int. J. Numerical Methods Eng., vol. 1, no. 36, pp. 945-967, 1993.

[18] R. Verma, D. D. Vecchio, and H. K. Fathy, "Development of a scaled vehicle with longitudinal dynamics of an HMMWV for an ITS test bed," IEEE/ASME Trans. Mechatron., vol. 13, no. 1, pp. 1-12, Feb. 2008.

[19] J. Yi, "A Piezo-sensor-based 'smart tire' system for mobile robots and vehicles," IEEE/ASME Trans. Mechatron., vol. 13, no. 1, pp. 95-103, Feb. 2008.
[20] C. Hsieh and G.-L. Lin, "Modeling and micro-radian precision pointing of a flexible manipulator with the existence of static friction," IEEE/ASME Trans. Mechatron., vol. 13, no. 1, pp. 148-157, Jan. 2008.

[21] W. Tsui, M. S. Masmoudi, F. Karray, I. Song, and M. Masmoudi, "Softcomputing-based embedded design of an intelligent wall/lane-following vehicle," IEEE/ASME Trans. Mechatron., vol. 13, no. 1, pp. 125-135, Feb. 2008.

[22] S.-L. Koo and H.-S. Tan, "Tire dynamic deflection and its impact on vehicle longitudinal dynamics and control," IEEE/ASME Trans. Mechatron., vol. 12, no. 6, pp. 623-631, Dec. 2007.

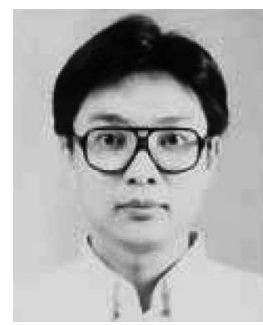

Jin-Chern Chiou received the M.S. and Ph.D. degrees in aerospace engineering science from the University of Colorado, Boulder, in 1986 and 1990, respectively.

He was a Research Associate at the Center for Space Structure and Control, University of Colorado at Boulder. Since 1992, he has been with the Department of Electrical and Control Engineering, National Chiao Tung University (NCTU), Hsin Chu, Taiwan. His current research interests include microelectromechanical systems, fuzzy-logic modeling, chemical vapor deposition process control, CD-ROM and DVD servo control, and multibody dynamic system modeling.

Dr. Chiou has received awards from the Acer Foundation, NCTU, and the Republic of China National Science Council for his CD-ROM and microelectromechanical systems (MEMS) research.

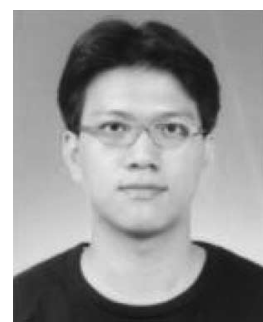

Chih-Liang Chen received the B.A.Sc. (with honors) degree in power mechanical engineering from the National Tsing Hua University, Hsinchu City, Taiwan, in 2001. He is currently working toward the $\mathrm{Ph} . \mathrm{D}$. degree at the Department of Electrical and Control Engineering, National Chiao Tung University, Hsin Chu, Taiwan.

His current research interests include vehicle dynamics, system modeling, and circuit design. 